OPEN ACCESS

Edited by:

Jiake $\mathrm{Xu}$,

University of Western Australia

Australia

Reviewed by:

Xinli Zhang,

University of California, Los Angeles,

United States

Shiwu Dong,

Third Military Medical University,

China

*Correspondence:

Guangwei Wang

guangwei_wang323@outlook.com

Yuanyuan Xiong

xiongyuanyuan_pub@126.com

Specialty section:

This article was submitted to

Molecular Medicine,

a section of the journal

Frontiers in Cell and Developmental

Biology

Received: 31 August 2020

Accepted: 23 November 2020

Published: 15 December 2020

Citation:

Liu Q, Li M, Wang S, Xiao Z Xiong Y and Wang G (2020) Recent Advances of Osterix Transcription Factor in Osteoblast Differentiation

and Bone Formation

Front. Cell Dev. Biol. 8:601224. doi: 10.3389/fcell.2020.601224

\section{Recent Advances of Osterix Transcription Factor in Osteoblast Differentiation and Bone Formation}

\author{
Qian Liu'1,2, Mao Li'2, Shiyi Wang ${ }^{3}$, Zhousheng Xiao4, Yuanyuan Xiong ${ }^{1,5 *}$ and \\ Guangwei Wang ${ }^{1,2 *}$
}

${ }^{1}$ Key Laboratory of Brain and Neuroendocrine Diseases, College of Hunan Province, Hunan University of Medicine, Huaihua, China, ${ }^{2}$ Biomedical Research Center, Hunan University of Medicine, Huaihua, China, ${ }^{3}$ XiangYa School of Medicine, Central South University, Changsha, China, ${ }^{4}$ Department of Medicine, University of Tennessee Health Science Center, Memphis, TN, United States, ${ }^{5}$ Department of Neurosurgery, The Second Affiliated Hospital of Nanchang University, Nanchang, China

With increasing life expectations, more and more patients suffer from fractures either induced by intensive sports or other bone-related diseases. The balance between osteoblast-mediated bone formation and osteoclast-mediated bone resorption is the basis for maintaining bone health. Osterix (Osx) has long been known to be an essential transcription factor for the osteoblast differentiation and bone mineralization. Emerging evidence suggests that Osx not only plays an important role in intramembranous bone formation, but also affects endochondral ossification by participating in the terminal cartilage differentiation. Given its essentiality in skeletal development and bone formation, Osx has become a new research hotspot in recent years. In this review, we focus on the progress of Osx's function and its regulation in osteoblast differentiation and bone mass. And the potential role of Osx in developing new therapeutic strategies for osteolytic diseases was discussed.

Keywords: osterix, osteoblast differentiation, therapy, osteolytic diseases, bone

\section{INTRODUCTION}

Nearly two decades ago, osterix (Osx) was first discovered by Nakashima et al. (2002). Osx, also known as Sp7, is a zinc finger-containing osteoblast-specific transcription factor belonging to the SP/KLF family (Nakashima et al., 2002; Suske et al., 2005). Its subcellular localization is restricted to the nucleus (Nakashima et al., 2002). Osx is expressed in osteoblast-lineage cells, chondrocytes and also overexpressed in various cancer tissues (Qu et al., 2019). The Osx protein is highly conserved between human and mouse with an overall amino acid sequence identity of $95 \%$. The transcription factor Osx induces the expression of a slew of mature osteoblast genes such as collagen typeI a1 (Col1a1), Osteonectin, Osteopontin, Osteocalcin, and Bone sialoprotein (Bsp) which are all necessary for productive osteoblasts during the creation of ossified bone (Renn and Winkler, 2009). In humans, several genome-wide association studies have demonstrated a correlation between Osx's certain polymorphisms and decreased bone mineral density in children and adults, and clinical 
researches revealed that Osx is associated with age-related osteoporosis (Calabrese et al., 2017; Kemp et al., 2017; Qaseem et al., 2017). This review aims to discuss the role of Osx in bone formation and bone mass control, signaling pathway network of Osx regulation, as well as Osx potential value in developing new therapeutic strategies for osteolytic diseases.

\section{THE STRUCTURE OF OsX}

Human Osx is located at chromosome 12q13.13 while in mice, it's located in chromosome 15q (Nakashima et al., 2002). The initial research found that Osx gene consists of three exons and two introns, with exon 2 contains the $5^{\prime}$ UTR and encodes a small part of amino acids, while exon 3 contains the $3^{\prime}$ UTR and encodes most of the protein (Nakashima et al., 2002; Gao et al., 2004). The Osx gene has a TATA-less promoter, and Osx regulates its own promoter through a tandem repeat CCACCC element in its proximal promoter (Barbuto and Mitchell, 2013). The Osx mRNA transcript is an approximately $3.2 \mathrm{~kb}$ sequence and three alternatively spliced mRNA variants have been identified with 5'RACE experiments (Gao et al., 2004). Because of the absence of initiation codon in the exon 1 and the same coding sequence between the transcript type I and type II, they eventually translated into the identical protein products (Gao et al., 2004). Therefore, the Osx protein can exist as either the long isoform $\alpha$ with 431 residues, derived from the transcript type I and II, or a short isoform $\beta$ with 413 residues, derived from the transcript type III. As a result, protein $\beta$ lacks the first $18 \mathrm{~N}$-terminal amino acids compared to protein $\alpha$, and both isoforms can be visualized on an immunoblot as bands at approximately 45 and $43 \mathrm{kDa}$, respectively (Milona et al., 2003; Gao et al., 2004; Ramazzotti et al., 2019). The difference between these two protein isoforms is the absence or presence of exon2. In addition, the amino acid sequence of the protein translated by Osx transcription factor was as high as $95 \%$, in which a transcriptional activation domain (TAD) rich in proline and serine at N-terminal (Gao et al., 2004). Osx protein is a sequence-specific DNA binding protein. Its DNA-binding domain is located at the C-terminus and contains three $\mathrm{C} 2 \mathrm{H} 2$-type zinc finger domains, which binds to SP1 and EKLF consensus sequences and to other G/C-rich sequences in the target genes (Nakashima et al., 2002). The schematic diagram of the Osx gene genome structure, mRNA transcript and its protein isoforms was shown in Figure 1.

\section{THE FUNCTION OF OsX IN CONTROLLING BONE FORMATION}

Up to now, it has been shown that Osx is specifically expressed in osteoblasts and osteocytes and, albeit at lower levels, in prehypertrophic and hypertrophic chondrocytes, while not expressed in osteoclasts (Xing et al., 2019). Osx not only plays a vital role in the differentiation, maturation or function of bone cells through the regulation of different genes, but also shows the potential role in the bone micro-environment. The schematic diagrams were summarized in Figure 2.

\section{The Function of Osx in Osteoblasts}

Osx has been confirmed to be involved in osteoblast differentiation, maturation and activity (Ramazzotti et al., 2019). It was reported that osteoblast differentiation does not occur at all in Osx-null embryos (Fu et al., 2010; Zhou et al., 2010). These studies demonstrated that Osx is essential for embryonic skeletal development. In Osx-deficient mice, the differentiation of runt-related transcription factor 2 (Runx2) expressing precursor cells was arrested and unable to express osteoblast markers (Zhou et al., 2010). When the vector expressing Osx was transfected into $\mathrm{C} 2 \mathrm{C} 12$ and C3H10T1/2 cells, Osteocalcin RNA was obviously induced by Osx in these two cell types and Collal gene expression was activated in C2C12 cells (Nakashima et al., 2002). Inactivation of Osx mice by CAG-CreER postnatally resulted in an arrest of osteoblast differentiation and of new bone formation, revealing that Osx also plays an indispensable functional role in postnatal skeletal growth and homeostasis (Zhou et al., 2010). An Osx mutation in zebrafish or medaka, belonging to non-mammals, resulted in a general delay in osteoblast maturation or severe bone defects and larval lethality (Azetsu et al., 2017; Niu et al., 2017; Yu et al., 2017), which established a key role of Osx for bone formation in non-mammalian species.

\section{The Function of Osx in Osteocytes}

Osx is necessary for the maturation and function of osteocytes postnatally (Baek and Kim, 2011; Klein-Nulend et al., 2013). Osx postnatal mutants appeared morphological osteocyte abnormalities, unlike normal osteocytes, and the expression levels of proteins encoded by "mineralization-related genes," such as Dmp1, Phex, and Sost, were significantly reduced (Zhou et al., 2010). The number of osteocytes close to both periosteum and endosteum was decreased and osteocytes were also markedly deformed. The mineralization process was seriously compromised in the Osx postnatal mutants. In both EMSA experiments and intact cells, Osx interacted with a specific site in the sclerostin promoter and activated this promoter in transfection assays, suggesting that Osx is also a player in mature osteocytes (Zhou et al., 2010).

\section{The Function of Osx in Chondrocytes}

The role of Osx in chondrocytes was first reported by Omoteyama and Takagi (2010). They investigated the in vitro effects of Osx gene silencing in the chondrogenic cell line ATDC5. Osx's shRNA down-regulated the expression of type $\mathrm{X}$ collagen (Col X), distal-less homeobox 5 (Dlx5) and alkaline phosphatase (Alp) mRNA, attenuated Alp enzyme activity, which suggests that Osx is involved in chondrogenic gene activation and chondrocyte differentiation. As for the in vivo effects, in Osx null mutants, there is no abnormality in the cellular organization of the cartilage growth plate (Nakashima et al., 2002). However, endochondral ossification completely stopped at the hypertrophic stage in chondrocyte-specific Osx conditional KO mice, even resulting in postnatal lethality combined with respiratory insufficiency (Omoteyama and Takagi, 2010; Oh et al., 2012). Massive accumulation of calcified 


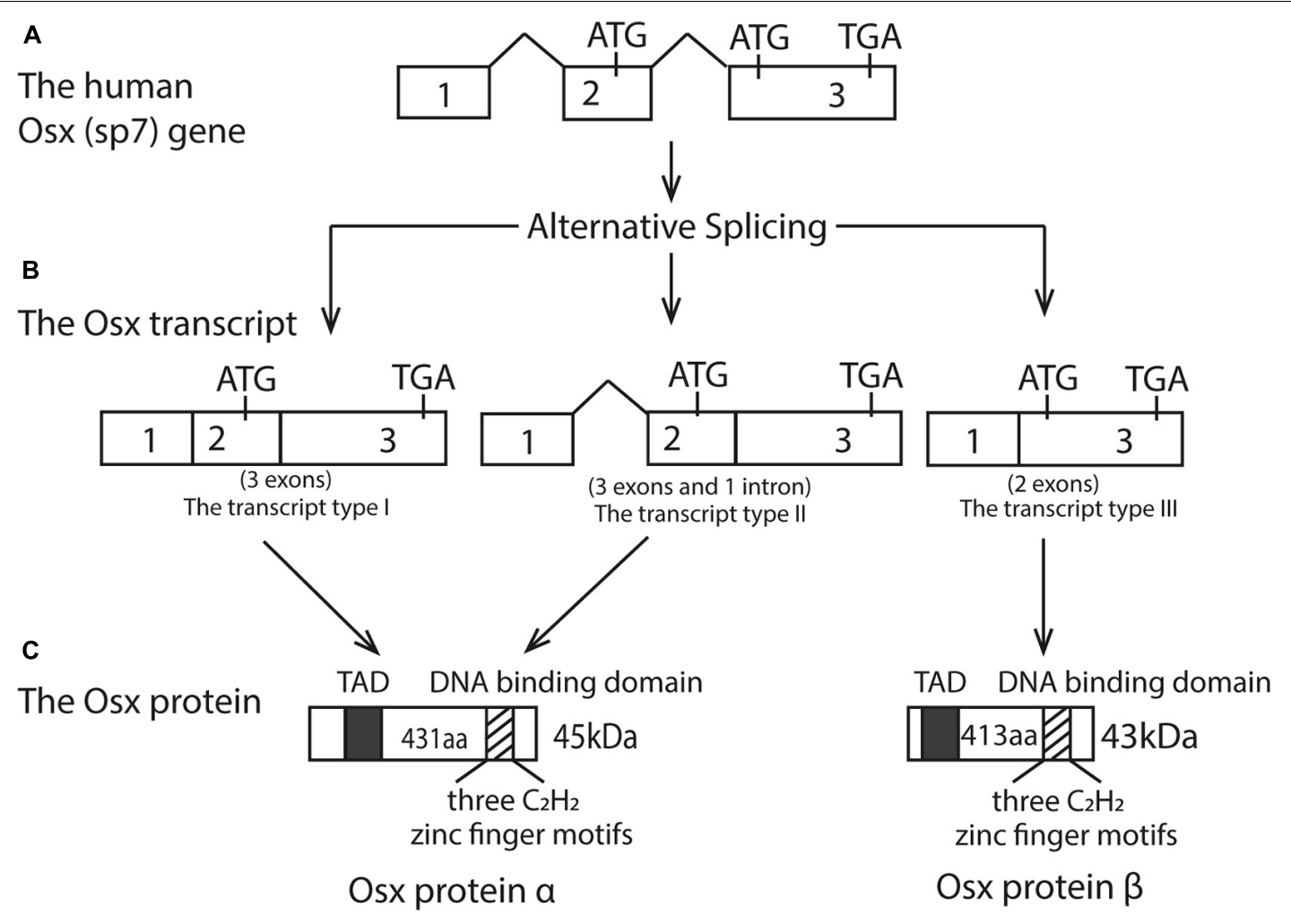

FIGURE 1 | Structure of the Osx gene, its three transcripts, and two protein isoforms. (A) Human Osx (sp7) gene; (B) The Osx transcripts; (C) The Osx protein isoforms. Open boxes represent exons and the thick line represents introns. Three alternatively spliced mRNA isoform were obtained. Because of the absence of initiation codon in the exonl and the same coding sequence between the transcript type I and type II, they eventually translated into the identical protein products. The transcript type III translated into a short protein isoforms with 413 aa. These two protein isoforms differ by the absence or presence of exon2. Therefore, Osx protein $\mathrm{B}$ lacks the first $18 \mathrm{~N}$-terminal amino acids compared to Osx protein $\alpha$. The black box represents $\mathrm{N}$-terminal transcriptional activation domain (TAD) rich in proline and serine. The striped box represents the DNA binding domain containing three $\mathrm{C} 2 \mathrm{H} 2$ zinc finger motifs near the $\mathrm{C}$-terminal.

cartilage and diminishment of bone trabecula were observed in Osx-floxed mice with the Col2a1-Cre-ERT2 transgene, which was caused by a delay in the development of hypertrophic chondrocytes and their conversion to osteoblasts (Zhou et al., 2010; Xing et al., 2019).

\section{The Function of Osx in Osteoclasts}

Although Osx is not expressed in osteoclasts, a number of scientific studies have suggested that Osx has different effects on osteoclasts. Receptor activator of NF-kappaB ligand (Rankl) signaling is the major determinant of osteoclast formation and activation, while osteoprotegerin (Opg) protects bone from excessive resorption by binding to Rankl. Their relative concentration is of great significance for bone mass and strength. A research conducted by Cao et al. (2005) found that the decrease of osteolysis was followed by Osx gene transfection, but the transfection of Osx did not inhibit Rankl expression. However, Zhou et al. (2010) have shown that the ratio of Opg/Rankl expression in long bones was increased in the Osx postnatal mutants. Consequently, the fewer overall number and size of osteoclasts was observed in Osx postnatal-null long bones. This contradicted result declared that more studies about the mechanisms of Osx's inhibiting effect on osteoclasts are necessary. Cytokines like interleukin-8 (IL-8) and parathyroid hormone-related protein (PTHrP) can cause bone destruction by inducing osteoclast differentiation and activation, they were also increased by Osx over-expression (Yao et al., 2019). An essential transcriptional factor for osteoclast differentiation named nuclear factor of activated T cells 1 (NFATc1) was also studied. It forms a complex with Osx and activates Osx-dependent Colla 1 promoter, suggesting that Osx has different effects on osteoclasts (Koga et al., 2005; Canalis et al., 2020).

\section{The Promising Role of Osx in the Complex Communications Among Different Bone Cells and Its Role in the Bone Micro-Environment}

The achievement and maintenance of a healthy and stable bone mass is accomplished through a close crosstalk among bone cells. Increasing evidences have shown that Osx not only performs multiple functions in different bone cells, but also participates in the cross-talk among them. Sclerostin (Sost) and Dickkopf-related protein 1 (Dkk1) are predominantly expressed in osteocytes, they exhibit a suppressive effect on osteoblast activity and function by antagonizing the Wingless-type and 


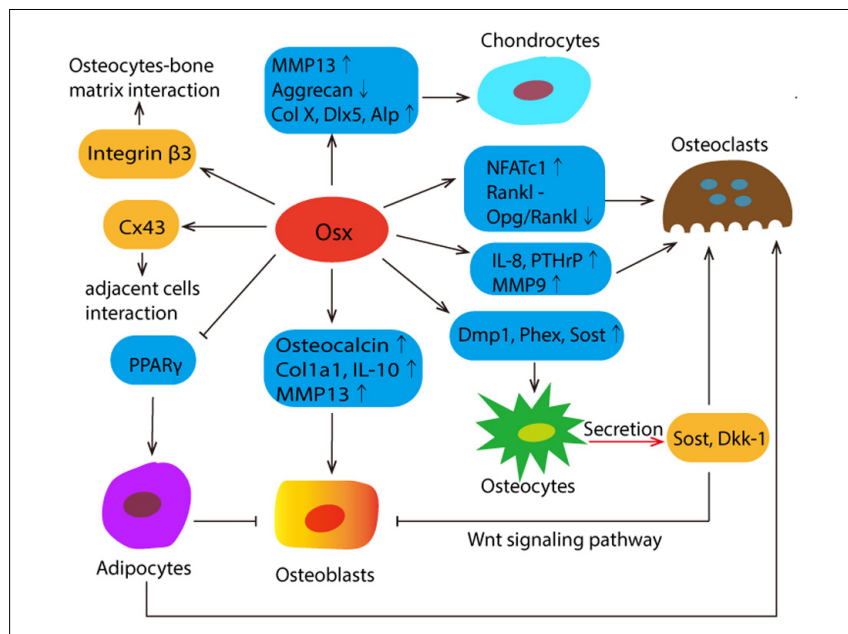

FIGURE 2 | The schematic summary of Osx's mission in the complex communications among different bone cells and its potential role in bone micro-environment. Osx affects the differentiation, maturation and function by regulating the different target genes, which were presented in the blue box. Osx directly controls the expression of integrin $\beta 3$, which plays a mediating role in osteocyte-bone matrix interaction. The most abundant gap junction protein Connexin43 (Cx43) was significantly regulated by Osx positively. Osx decreases osteoblast activity by stimulating the expression of sclerostin (Sost) and Wnt signaling pathway inhibitor Dickkopf-related protein 1 (Dkk1). Both of them are predominantly expressed in osteocytes. And Sost also functions as a secreted osteoclast-derived BMP antagonist to promotes osteoclast differentiation. In addition, Osx represses adipogenesis by negatively regulating PPARy expression and transcriptional activity, and adipocytes suppress osteoblasts and promote bone resorption by the recruitment of osteoclasts.

Int (Wnt) signaling pathway. Osx decreases osteoblast activity by stimulating the expression of Sost and Dkk1. As a secreted osteoclast-derived BMP antagonist, Sost not only inhibits osteoblast differentiation but also promotes osteoclast differentiation (Kusu et al., 2003). In addition to this, Osx can activate the Sost promoter and specifically bind to a DNA fragment located within the promoter (Cao et al., 2015; Zhang Z. H. et al., 2020). The osteocytes are surrounded by a nonorganized pericellular matrix and integrins play a mediating role in osteocyte-bone matrix interaction. Osx directly controls the expression of integrin $\beta 3$, which regulates corticalization for longitudinal bone growth (Moon et al., 2018). Osteoblasts and osteoclasts can communicate with each other. Osteoclasts produce factors called clastokines controlling osteoblasts during the bone remodeling cycle. Matrix metalloproteinase-9 (MMP9), predominantly produced by osteoclasts in bone, have an important function at the injured bone absorption, healing and bone remodeling after dental implant placement. It was reported that MMP9 initiates osteoclasts by removing collagen from the demineralized bone (Liu et al., 2004; Chen et al., 2018; Zhang H. et al., 2020). MMP9 is the target of Osx, in which Osx is recruited to the MMP9 promoter and binds to the CCAAT regulatory element of MMP9 promoter. Correspondingly, it has been clearly demonstrated that osteoblasts also affect the activity of osteoclasts, and Osx participates in the cross-talk between them by up-regulating factors expressed in osteoblasts such as Matrix metalloproteinase-13 (MMP13) (Hayami et al., 2011; Nakatani et al., 2016). MMP13 is expressed in hypertrophic chondrocyte and osteoblast. It contributes significantly to differentiation of osteoblast. Meanwhile, MMP13 also plays a significant role in differentiation and activation of osteoclast (Hayami et al., 2011; Pivetta et al., 2011; Nakatani et al., 2016). In osteoblasts, Osx activates the MMP13 promoter activity in a dose-dependent manner (Zhang et al., 2012). These studies suggested that Osx is involved in the interaction of osteoblast and osteoclast by mediating different factors. As the most abundant gap junction protein in bone cells, Connexin43 ( $\mathrm{Cx} 43)$ participates in the communication between adjacent cells, as well as cells and extracellular environment (Chen et al., 2019). It was reported that $\mathrm{Cx} 43$ expression was significantly repressed by the addition of shRNA against Osx, whereas overexpression of Osx resulted in enhanced $\mathrm{Cx} 43$ expression. Further studies have proven that Osx can directly occupy the promoter region of $\mathrm{Cx} 43$ and subsequently increases Cx43 promoter activity in a dosedependent manner (Han et al., 2016a; Chen et al., 2019). Recent studies have shown that bone marrow adipocytes not only suppress osteoblasts, but also promote bone resorption by the recruitment of osteoclasts, and Osx represses adipogenesis by negatively regulating PPAR $\gamma$ expression and transcriptional activity (Han et al., 2016b; Li et al., 2018b).

\section{Osx PROMOTES OSTEOGENESIS THROUGH THE REGULATION OF DOWNSTREAM FACTORS}

The essential role of Osx in osteoblast differentiation is attributed to its ability to regulate the expression of various osteoblast markers such as Bsp, fibromodulin, Osteocalcin, Dkk1 and Colla1, etc. (Wu et al., 2007; Ortuno et al., 2013; Yang et al., 2016; Niu et al., 2017). In addition to these target genes previously discovered, several novel downstream targets of Osx have been identified. Zinc finger and BTB domain containing 16 (Zbtb16), a downstream target gene of Osx, functions as a late marker of osteoblastic differentiation and regulates osteogenesis of human multipotent mesenchymal stromal cells (Onizuka et al., 2016). Fibrillin-2 and periostin are also identified to be target candidates of Osx in osteoblast differentiation (Lee et al., 2017). Besides, Osx regulates corticalization by controlling integrin $\beta 3$ expression directly (Moon et al., 2018). Osx increases the promoter activity of $\mathrm{Cx} 43$ by directly interacting with the $\mathrm{Cx} 43$ promoter and subsequently upregulates the expression level of Cx43. As a result, the expression and transcriptional activity of $\mathrm{Cx} 43$ were considerably affected by Osx (Han et al., 2016a).

It is generally recognized that the canonical Osx pathway usually involves binding to GC-box DNA elements to regulate the transcription of target genes. Osx is able to activate Bsp promoter reporter in a dose-dependent manner, and one GCrich site is required for Bsp promoter activation by Osx directly (Yang et al., 2016). Contrary to expectation, it has been reported that Osx acts as a transcriptional co-activator in the distal-less homeobox (Dlx) regulatory complex that binds to AT-rich motifs (Hojo et al., 2016). It's obvious from this point 
that Osx can also form complexes with other transcription factors to co-regulate downstream target genes. Osx can also interact with Runx2 to coordinately activate the expression of the various genes, and their synergistic effects achieve significantly higher expression levels than those obtained with the individual expression vectors. Colla1, Sost, Ectonucleotide pyrophosphatase/phosphodiesterase 1(Enpp1) and the novel gene unique cartilage matrix-associated protein (Ucma) have been reported to be their coordinated target genes (Ortuno et al., 2013; Lee Y. J. et al., 2015; Pérez-Campo et al., 2016; Gao M. et al., 2018). The interaction of Osx and Runx 2 in the regulation of these promoters is mediated by Osx's enhancer regions adjacent to Sp1 and Runx2 DNA-binding sites, thereby synergistically regulating those downstream genes transcription.

More notably, both Runx2 and Osx are induced by $\mathrm{Zn}^{2+}$ influx, and they transcriptionally regulated ZIP1 expression which further leads to induction of $\mathrm{Zn}^{2+}$ influx contributing to a positive feed-forward zinc-Runx2/Osx-ZIP1 regulation loop during osteogenic differentiation (Karieb and Fox, 2012; Fu et al., 2018). NFATc1 forms a complex with Osx and activates Osxdependent Colla 1 promoter, however it does not activate Runx2dependent transcription. Furthermore, transcriptional regulators such as p300, Brg1 or NO66 have been shown to interact with Osx and regulate its transcriptional activity (Ortuño et al., 2010; Sinha et al., 2014). It is noteworthy that Osx and NO66 histone demethylase control the chromatin of its target genes, in which Osx acts as a molecular switch for the formation of an active chromatin state during osteoblast differentiation, whereas NO66 suppresses gene through histone demethylation and/or formation of a repressor complex. Osx and NO66 work together to achieve multi-layered control of the chromatin structure of target genes (Sinha et al., 2010; Sinha et al., 2014).

The investigation of downstream targets of Osx contributes to elucidate its molecular mechanism affecting osteoblast differentiation and bone formation, thereby further promoting the exploration of new regulatory mechanisms involving Osx. The Osx direct and indirect downstream targeting molecules for osteoblastic differentiation and their mode of action (MOA) were sumarized in Table $\mathbf{1 .}$

\section{THE SIGNALING PATHWAYS CONTROL OsX EXPRESSION}

There are two main pathways which cause in the induction of Osx gene expression, indirectly or directly (Ramazzotti et al., 2019). We will discuss these two signaling pathways in detail below. The overview of crosstalk pathways associated with Osx were showed in Figure 3.

\section{Runx2-Dependent Pathways}

It has been extensively recognized that Osx functions as downstream of Runx2, since the latter is expressed in mesenchymal cells of Osx $\mathrm{KO}$ mice while Osx expression is not observed in the absence of Runx2 (Komori, 2018). For the Runx2dependent pathway, it is usually activated by bone morphogenic protein (BMP) signals (Li et al., 2017, 2018a; Lee et al., 2019).
TABLE 1 | The Osx direct and indirect downstream targeting molecules for osteoblastic differentiation and their mode of action (MOA).

\begin{tabular}{|c|c|c|c|}
\hline Target genes & MOA of Osx & Functions & Reference(s) \\
\hline Bsp & $\begin{array}{l}\text { By binding to specific GC-rich } \\
\text { site directly }\end{array}$ & $\begin{array}{l}\text { Up- } \\
\text { regulation }\end{array}$ & Yang et al., 2016 \\
\hline Fibromodulin & $\begin{array}{l}\text { By binding to specific GC-rich } \\
\text { site directly }\end{array}$ & $\begin{array}{l}\text { Up- } \\
\text { regulation }\end{array}$ & $\begin{array}{l}\text { Ortuño et al., } \\
2010\end{array}$ \\
\hline Sost & $\begin{array}{l}\text { By binding to specific GC-rich } \\
\text { site directly and activating Sost } \\
\text { expression with Runx2 in a } \\
\text { co-ordinated manner }\end{array}$ & $\begin{array}{l}\text { Up- } \\
\text { regulation }\end{array}$ & $\begin{array}{l}\text { Yang et al., 2010; } \\
\text { Pérez-Campo } \\
\text { et al., } 2016\end{array}$ \\
\hline Periostin & $\begin{array}{l}\text { By binding to specific GC-rich } \\
\text { site directly }\end{array}$ & $\begin{array}{l}\text { Up- } \\
\text { regulation }\end{array}$ & Lee et al., 2017 \\
\hline Osteocalcin & $\begin{array}{l}\text { By binding to the CCAAT } \\
\text { sequence directly }\end{array}$ & $\begin{array}{l}\text { Up- } \\
\text { regulation }\end{array}$ & Niger et al., 2011 \\
\hline Dkk1 & $\begin{array}{l}\text { By enhancing Dkk1 expression } \\
\text { directly }\end{array}$ & $\begin{array}{l}\text { Up- } \\
\text { regulation }\end{array}$ & Cao et al., 2015 \\
\hline Col1a1 & $\begin{array}{l}\text { By binding the Sp1 boxes } \\
\text { directly or forming a complex } \\
\text { with NFATc1 to upregulate the } \\
\text { Col1a } 1 \text { expression indirectly }\end{array}$ & $\begin{array}{l}\text { Up- } \\
\text { regulation }\end{array}$ & $\begin{array}{l}\text { Koga et al., 2005; } \\
\text { Ortuno et al., } \\
2013\end{array}$ \\
\hline Col1a2 & $\begin{array}{l}\text { By binding to the second } \\
\text { GC-rich site directly }\end{array}$ & $\begin{array}{l}\text { Up- } \\
\text { regulation }\end{array}$ & Yano et al., 2014 \\
\hline Col5a1 & $\begin{array}{l}\text { By binding to GC-rich } \\
\text { sequence directly }\end{array}$ & $\begin{array}{l}\text { Up- } \\
\text { regulation }\end{array}$ & $\begin{array}{l}\text { Wu et al., } \\
2010 a, b\end{array}$ \\
\hline Col5a3 & $\begin{array}{l}\text { By binding to GC-rich } \\
\text { sequence directly }\end{array}$ & $\begin{array}{l}\text { Up- } \\
\text { regulation }\end{array}$ & $\begin{array}{l}\text { Wu et al., } \\
2010 a, b\end{array}$ \\
\hline Zbtb16 & $\begin{array}{l}\text { By binding to the SP1-binding } \\
\text { site directly }\end{array}$ & $\begin{array}{l}\text { Up- } \\
\text { regulation }\end{array}$ & $\begin{array}{l}\text { Onizuka et al., } \\
2016\end{array}$ \\
\hline Integrin $\beta 3$ & $\begin{array}{l}\text { By binding to the integrin } \beta 3 \\
\text { promoter directly }\end{array}$ & $\begin{array}{l}\text { Up- } \\
\text { regulation }\end{array}$ & Moon et al., 2018 \\
\hline $\mathrm{C} \times 43$ & $\begin{array}{l}\text { By binding to the promoter } \\
\text { region of } \mathrm{Cx} 43 \text { directly }\end{array}$ & $\begin{array}{l}\text { Up- } \\
\text { regulation }\end{array}$ & Han et al., 2016a \\
\hline $\begin{array}{l}\text { Vascular } \\
\text { endothelial } \\
\text { growth factor } \\
\text { (VEGF) }\end{array}$ & $\begin{array}{l}\text { By binding to the promoter } \\
\text { directly or regulating gene } \\
\text { expression of VEGF with } \\
\text { HIF-1 } \alpha \text { cooperatively }\end{array}$ & $\begin{array}{l}\text { Up- } \\
\text { regulation }\end{array}$ & $\begin{array}{l}\text { Chen et al., 2012; } \\
\text { Tang et al., } 2012\end{array}$ \\
\hline MMP13 & $\begin{array}{l}\text { By binding to the GC-rich } \\
\text { sequence directly }\end{array}$ & $\begin{array}{l}\text { Up- } \\
\text { regulation }\end{array}$ & $\begin{array}{l}\text { Zhang et al., } \\
2012\end{array}$ \\
\hline MMP9 & $\begin{array}{l}\text { By binding to the CCAAT } \\
\text { sequence directly }\end{array}$ & $\begin{array}{l}\text { Up- } \\
\text { regulation }\end{array}$ & Yao et al., 2019 \\
\hline $\mathrm{ZIP1}$ & $\begin{array}{l}\text { By regulating gene ZIP1 } \\
\text { expression of VEGF with Runx2 } \\
\text { cooperatively }\end{array}$ & $\begin{array}{l}\text { Up- } \\
\text { regulation }\end{array}$ & Fu et al., 2018 \\
\hline Ucma & $\begin{array}{l}\text { By binding to Sp1-binding sites } \\
\text { directly }\end{array}$ & $\begin{array}{l}\text { Up- } \\
\text { regulation }\end{array}$ & $\begin{array}{l}\text { Lee Y. J. et al., } \\
2015\end{array}$ \\
\hline Enpp1 & $\begin{array}{l}\text { By binding to Sp1-binding sites } \\
\text { directly }\end{array}$ & $\begin{array}{l}\text { Up- } \\
\text { regulation }\end{array}$ & $\begin{array}{l}\text { Gao M. et al., } \\
2018\end{array}$ \\
\hline Fibrillin-2 & Unknown & $\begin{array}{l}\text { Down- } \\
\text { regulation }\end{array}$ & Lee et al., 2017 \\
\hline
\end{tabular}

Interestingly, Osx was also first discovered as a BMP2 induced gene (Lee et al., 2003). BMP2 plays a unique role in mesenchymal stem cells (MSCs) differentiation by controlling the transition from progenitors to $\mathrm{Runx}^{2+} \mathrm{Osx}^{+}$cells. Osx expression is not regulated by the orchestration of the BMP signaling pathways directly and specifically but eventually by crucial transcriptional factors (Matsubara et al., 2008). BMP2 is proved to activate Runx2 through Smad signaling and Runx2 in turn up-regulates Osx expression, in which Runx 2 directly binds to Osx promoter 


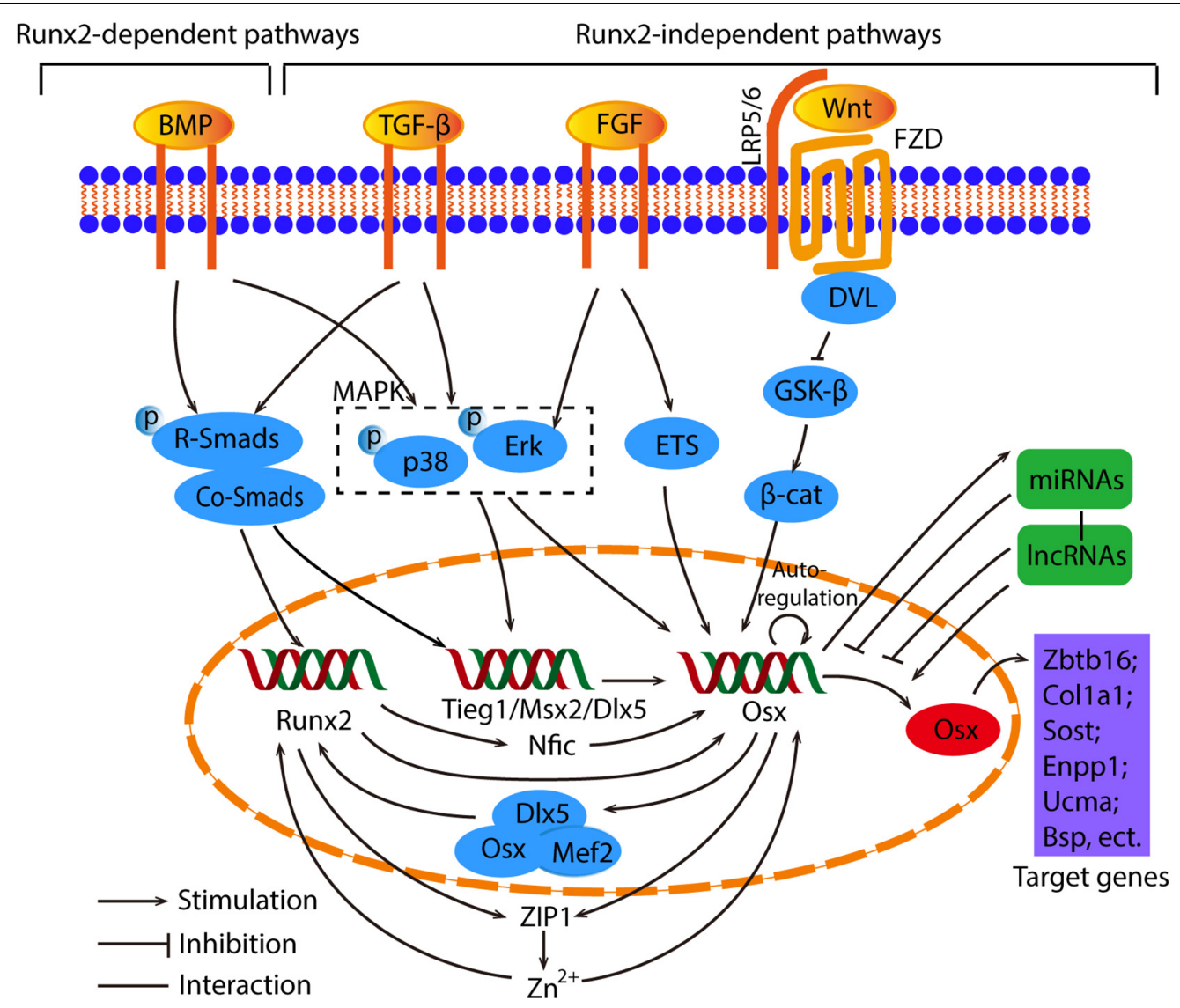

FIGURE 3 | The overview of crosstalk pathways associated with Osx. The signaling pathways that control Osx expression can be divided into Runx2-dependent and Runx2-independent pathways. In regard to the Runx2 dependent pathways, the BMP/Smads/Runx2 is the canonical pathway, and Runx2 regulates Osx by Nfic, ZIP1 indirectly or upregulate Osx directly. Meanwhile, Osx cooperate with DIx5 and Mef2 to control Runx2 reversely. As for the Runx2-independent pathway, they are induced by BMP, TGF- $\beta$ and FGF, then activate Smads, MAPK or ETS to regulate Osx directly or indirectly. The Wnt/ $\beta$-catenin signaling is involved in the suppression of Osx. What's more, Osx has the capability of auto-regulation. Osx are also controlled by miRNAs and IncRNAs in an epigenetic manner. Generally, miRNAs act as negative regulators and Osx conversely stimulates miRNAs. Different IncRNAs regulate Osx positively or negatively. Eventually, Osx promotes osteogenesis through the regulation of downstream factors such as Zbtb16, Col1a1, Sost, etc.

region and regulates Osx promoter activity (Xiao et al., 2004; Pérez-Campo et al., 2016; Takarada et al., 2016). Nuclear factor I-C (Nfic), expressed in human osteoblasts and osteoblast-like cell lines, was found to be a new candidate gene that participate in osteogenic differentiation. It acts as an intermediary transducer between Runx 2 and Osx in the BMP2 signaling pathway where Runx2 is upstream of Nfic and Nfic directly controls Osx expression (Lee et al., 2014; Zhang et al., 2015; Lee et al., 2018). Osx is localized on the enhancer region in primary osteoblasts, and can form an enhanceosome with Dlx 5 and myocyte enhancer factor 2 (Mef2) to synergistically activate an osteoblast-specific enhancer of Runx2, demonstrating that Osx is also involved in the regulation of Runx2 expression (Kawane et al., 2014). These suggest that the regulation between Osx and Runx2 works like a positive loop indirectly.

\section{Runx2-Independent Pathways}

Despite both Runx2 and Osx control bone mineralization and MSCs differentiation, the bone phenotype of Osx-deficient mice differ from that of Runx2-deficient mice (Nakashima et al., 2002; Caparros-Martin et al., 2013), indicating their distinctive functions during the process of bone formation. Osx could even bind and stimulate the upstream CCACCC site in its promoter to regulate its own expression, forming a positive feedback mechanism (Barbuto and Mitchell, 2013). It has been shown that BMP2 and Msh homeobox 2 (Msx2) induced Osx expression in Runx2-deficient mesenchymal cells, and the knockdown of Msx2 blocked the induction of Osx in the Runx2-deficient MSCs, which indicates that BMP2 regulates Osx expression through Msx2 independently of Runx2 (Matsubara et al., 2008). Similarly, a novel factor necessary for optimal expression of Osx in osteoblasts, namely TGF $\beta$-induced early gene 1 (Tieg1), is also required for BMP2 and TGF $\beta$-mediated Osx expression. It directly regulates the expression of Osx by binding to its proximal promoter (Subramaniam et al., 2016; Rajamannan, 2019).

According to reports, MAPK is also involved in the BMP2induced Osx expression (Sun et al., 2018). BMP2-mediated enhancement of Osx mRNA transcription is achieved through 
the activation of Dlx 5 by p38 and extracellular signal-regulated kinase (Erk)-mediated phosphorylation. During this process, the Dlx5 binds to the Osx promoter and recruits p300, a co-activator, to increase the stability of Osx (Lee et al., 2003; Choi et al., 2011a; Xiao et al., 2015; Abdallah et al., 2018). Based on the studies of the signaling pathways related to MAPK, the mechanism of osteoporosis treatment is being further understood. For example, a significant decreases in the protein levels of Runx2 and Osx under Erk1/2, p38, or c-Jun-N-terminal kinase (JNK) signaling inhibitor treatment in $\beta$-tricalcium phosphate $(\beta-\mathrm{TCP}) / \mathrm{Mg}-\mathrm{Zn}$ composite can be observed easily, indicating that $\mathrm{Mg}^{2+}$ in $\mathrm{Mg}-\mathrm{Zn}$ extract promotes osteogenic differentiation via p38 MAPKregulated Osx (Wang Z. et al., 2020).

The wingless-related integration site (Wnt) pathway modulates bone formation through the control of progenitor cells proliferation and differentiation (Sun et al., 2016; Jing et al., 2018; Yang et al., 2020). The Wnt1 class activates the canonical Wnt signaling pathway by binding to lipoprotein receptor-related protein 5 and 6 (LRP5/6). And the canonical Wnt signaling pathway increases the stability and accumulation of $\beta$-catenin in the cytoplasm, therefore facilitating the entry of $\beta$-catenin into the nucleus to promote target genes Osx transcription (Liu et al., 2015; Nemoto et al., 2016; Shi et al., 2016). A process in the developing facial skeleton was investigated and showed that Osx is a transcriptional target of the fibroblast growth factors (FGFs) pathway. Its manipulation has an immediate and strong effect on Osx expression and FGFs directly activate Osx expression via a shared intronic cis-regulatory module. The activity of the FGFs pathway was modulated by $\mathrm{Wnt} / \beta$-Catenin pathway, and the interactions between FGFs and Wnt/ $\beta$-Catenin signaling pathways were mediated by ETS factors (Felber et al., 2015). Wnt3a upregulates Osx expression through activation of p38 MAPK in dental follicle cells, but p38 MAPK signaling has no crosstalk with phosphorylation of the glycogen synthase kinase$3 \beta$ (GSK3 $\beta$ ) and accumulation or translocation of $\beta$-catenin (Sakisaka et al., 2016). Osx can synchronously work with HIF-1 $\alpha$ to further inhibit $\beta$-catenin activity. Similarly, Osx suppresses the activity of the canonical Wnt signaling pathway in osteoblasts by activating the Wnt antagonist Dkk1 (Cao et al., 2015).

\section{OTHER FACTORS IN THE BONE MICROENVIRONMENT INTERACT WITH Osx}

The secretion of hormones and cytokines in the bone microenvironment has a significant effect on the differentiation of osteoblasts and osteoclasts. And these molecules interact with Osx to influence osteogenic differentiation, which provides new avenues to develop therapeutic strategies for osteolytic diseases.

It is well-known that estrogen (ER) deficiency has clearly been established as seminal mechanism in the pathogenesis of osteoporosis (Farr et al., 2019). The lack of estrogen leads to disorders in the regulation of cytokines, growth factors and humoral factors in the bone microenvironment. And the molecular mechanism for the role of ER in bone cells is being unraveled gradually. Interestingly, it has been certificated that ER exert its function of promoting osteogenic differentiation by elevating Osx expression (Han et al., 2020). Parathyroid hormone $(\mathrm{PTH})$ has been proved to increase the Osx expression levels (Yang et al., 2019). Secretion of melatonin is regulated by the suprachiasmatic nucleus of the hypothalamus. Recently, several findings have demonstrated that melatonin regulates Osx expression through inhibition of the ubiquitin-proteasome system, and therefore increases Osx-mediated Alp activity, matrix mineralization, and transcriptional activity. Furthermore, the occupancy of Osx at the promoter of the Bsp gene is also enhanced by melatonin. Researchers believe that melatonin may be a potent osteogenic agent in the treatment of osteoporosis (Machida et al., 2006; Han et al., 2017; Choi et al., 2018; Zhou et al., 2020). Another hormone neuropeptide Y, produced by osteoblasts and other peripheral tissues, was also proved to directly promote osteogenic differentiation of MC3T3-E1 cells by upregulating Osx in vitro (Zhang B. et al., 2020).

The bone is the third most common site of metastasis for a wide range of solid tumors. When metastatic cancer cells invade the bone, the crosstalk between tumor cells and the bone microenvironment disrupts the bone homeostasis. It was reported that galectin-3, a tumor-secreted sugar-binding protein, regulates the expression of Osx, thereby remodeling bone in the bone microenvironment niche (Nakajima et al., 2014). Opn released from cancer stem cells acts as a stimulator of osteogenesis by regulating Osx (Kim et al., 2019). In addition, expressions of two cytokines, interleukin-8 (IL-8) and parathyroid hormonerelated protein (PTHrP), that cause bone destruction by inducing osteoclast differentiation and activation, were increased by Osx over-expression. On the contrary, there is low IL-8 and PTHrP expression in the tumors with Osx-knockdown cells (Yao et al., 2019). Interleukin-10 (IL-10), a cytokine that directly increases osteoblast differentiation and inhibits osteoclast differentiation, is able to up-regulate Osx gene expression in osteoblasts via mitogen-activated protein kinase (MAPK) pathway (RiosArce et al., 2020). These results demonstrated that Osx has potential regulatory effects on various molecules in the bone microenvironment.

\section{miRNAs AND IncRNAs REGULATE Osx EXPRESSION}

\section{Osx Is Regulated by IncRNAs in an Epigenetic Manner}

Long non-coding RNAs (lncRNAs), a novel subset of nonprotein-coding RNAs with longer than 200 nucleotides was established to regulate Osx epigenetically (Wu J. et al., 2018; Wu R. et al., 2018; Jiang et al., 2019; Wang et al., 2019). It was found that the regulation of osteoblast activity by lncob1 is dependent on Osx. lnc-ob1 binds Suz12, a subunit of the Polycomb Repressive Complex 2, to control H3K27me3 methylation at the Osx promoter, thereby effectively regulating the Osx mRNA levels and protein levels (Sun et al., 2019). A recent report illustrated a novel mechanism of Osx during the osteogenic differentiation, that is, IncRNAs regulate Osx expression via a Runx2-independent pathway. Overexpression or knockdown of lncRNA ODIR1(Osteogenic differentiation 


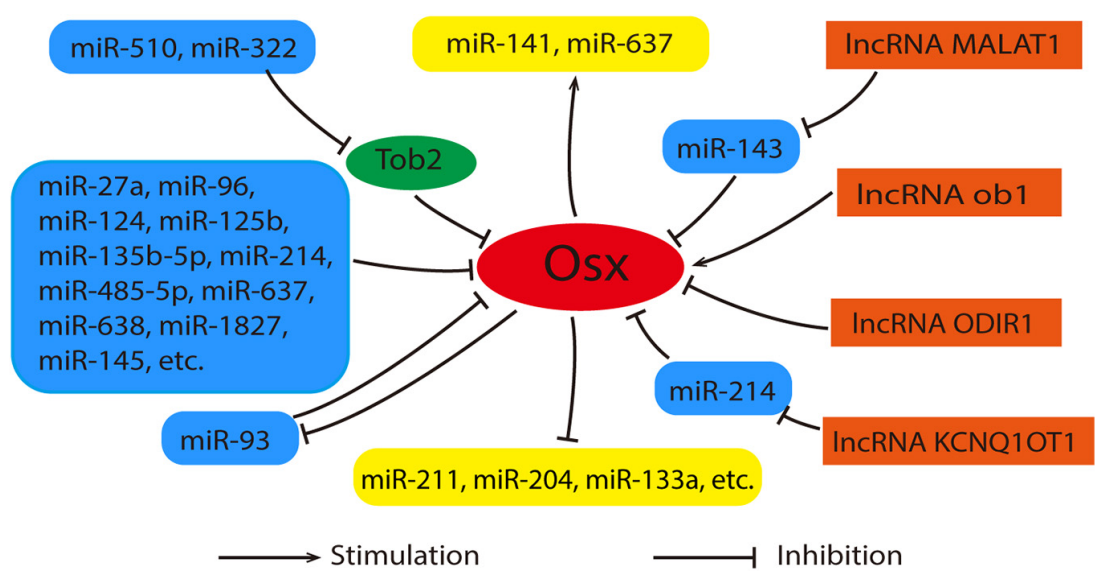

FIGURE 4 | Relationships between Osx, miRNAs and IncRNAs. Generally, miRNAs act as inhibitors during the regulation of Osx. These miRNAs were listed in the left with blue. Among them, miR-322 and rmiR-510 promote Osx expression via the inhibition of Tob2 indirectly. Meanwhile, Osx also has feedback effects on the miRNAs expression positively or negatively. These miRNAs were listed in the middle with yellow. IncRNAs (orange) control the expression of Osx in an direct or indirect manner. As for the indirect way, miRNAs can serve as their intermediary.

inhibitory regulator 1) significantly reduced or increased the expression levels of the mRNA and protein level of Osx in the osteogenic differentiation of MSCs while Runx2 was not altered, which strongly indicates that IncRNA ODIR1-mediated Osx expression is not dependent on Runx2. Further research showed that lncRNA ODIR1 inhibits Osx transcription by altering the modification of histone marks on Osx promoter. Increased expression level of F-box protein 25 (FBXO25) by knockdown of IncRNA ODIR1 in human umbilical cord-derived MSCs promoted H2BK120 mono-ubiquitylation which stimulated H3K4 trimethylation, and then the transcription level of Osx was elevated, in which both H2BK120ub and H3K4me3 form a loose chromatin structure and induce Osx expression ( $\mathrm{He}$ et al., 2019). Consequently, these studies demonstrated that Osx has become a key regulator for researching the mechanism of lncRNAs involved in osteogenic differentiation, and it would be performed to develop novel therapeutic strategies for osteoporosis.

\section{miRNAs Participate in Epigenetic Regulation of Osx During Osteogenic Differentiation}

As an important post-transcriptional regulator, microRNAs (miRNAs) participate in the osteogenic differentiation of MSCs by targeting multiple genes including Runx2, Dlx, Smad4, etc. (Landgraf et al., 2007; Huang et al., 2016). It has been proved that miR-27a and miR-96 etc. regulate osteogenesis by targeting Osx (As shown in Figure 4) (Zhang et al., 2011; Shi et al., 2013; Zhang et al., 2018; Jiao et al., 2019). They suppress osteogenic differentiation by decreasing Osx expression directly. Recently, Liu et al. (2020) have certified that Osx serves as the direct target of miR-1827 and the inhibitive effect on osteogenic differentiation of miR-1827 amplification was reversed by Osx overexpression. In addition to this, some miRNAs indirectly regulated the expression of Osx via other genes. miR-322 and miR-510 promoted Osx expression via the inhibition of Tob2, a negative regulator of osteogenesis that bound and mediated the degradation of Osx mRNA (Gamez et al., 2013; Wang et al., 2017). Interestingly, a study revealed that Osx also has feedback effects on the miRNAs expression. It was reported that miRNA-93 is able to form a feedback loop with Osx to regulate osteoblast mineralization (Yang et al., 2012). The details were shown in Figure 4.

\section{IncRNAs Interact With miRNAs to Regulate Osx}

Since both miRNAs and lncRNAs have such vital functions in Osx-mediated osteogenic differentiation, is there a possibility that lncRNAs interact with miRNAs to regulate Osx? Some experimental findings correlate with this point of view. In human bone marrow-derived MSCs, lncRNA Metastasis-associated lung adenocarcinoma transcript-1 (MALAT1) is able to increase Osx expression by competitively binding to miR-143 and inhibit its expression, since miR-143 inhibits Osx expression (Gao Y. et al., 2018). Recently, it has been also reported that IncRNA KCNQ1OT1 promotes osteogenic differentiation of bone marrow mesenchymal stem cells (BMSCs) by sponging miR-214 as a competing endogenous RNA via regulating BMP2/Smad pathway (Wang et al., 2019). Obviously, the new molecular mechanism of the interaction between Osx, miRNAs and IncRNAs in regulation of osteogenic differentiation of BMSCs still remains to be explored. For intuitive description, Figure 4 shows the relationships between Osx, miRNAs and lncRNAs clearly.

\section{POST-TRANSLATIONAL MODIFICATIONS ARE IMPORTANT FOR OsX ACTIVITY}

Post-translational modification is a key cellular event in controlling the activities of Osx during osteogenic differentiation.

Osteoblast activity is augmented in ubiquitin ligase-deficient mice that generate adult onset osteosclerosis with increased bone 
mass, indicating that the ubiquitin-proteasome system plays a role in osteoblast differentiation. Generally speaking, proteins are ubiquitinated and then degraded by proteasome. Further studies demonstrated that ubiquitination of Osx plays a key role in osteoblast differentiation. K58 and K230 were first identified to be the ubiquitination sites of Osx by Co-IP assays and protein stability assays (Peng et al., 2013). Subsequently, it has been illustrated that ring finger type E3 ubiquitin ligases Cbl-b and $\mathrm{c}$ - $\mathrm{Cbl}$ enhance ubiquitin-proteasome-mediated degradation of Osx by reducing the protein stability of Osx in BMP2stimulated C2C12 cells (Choi et al., 2015). However, Cbl-b and $\mathrm{c}-\mathrm{Cbl}$ did not affect the protein levels of other osteogenic transcription factors such as Dlx3, Dlx5, and Msx2. These results suggest that $\mathrm{Cbl}-\mathrm{b}$ and $\mathrm{c}-\mathrm{Cbl}$ specifically regulate the function of Osx during osteoblast differentiation. CHIP, another novel post-translational regulator of Osx, plays an important role in the regulation of Osx in protein levels in osteoblast precursor cells upon treatment with tumor necrosis factor- $\alpha$ (TNF- $\alpha$ ). Unlike the previous description, CHIP mediates the inhibition of Osx by TNF- $\alpha$ in K55 and K386 ubiquitination sites of Osx (Xie and $\mathrm{Gu}, 2015$ ).

Phosphorylation is widely recognized as an important regulatory pathway in skeletal development and maintenance. Osx can be regulated post-translationally by protein kinasemediated phosphorylation including NFATc1, protein kinase B (Akt), kinase glycogen synthase kinase-3 (GSK-3), Peptidyl-prolyl isomerase 1 (Pin1) and Erk, etc. in osteoblast differentiation (Koga et al., 2005; Choi et al., 2011b; Qi et al., 2015). Akt is a member of serine/threonine-specific protein kinase that phosphorylates Osx and its activation increases protein stability, osteogenic and transcriptional activity of Osx (You et al., 2011). Mammalian GSK-3, consisting of two isoforms GSK- $3 \alpha$ and GSK-3 $\beta$, plays a vital role in the functional regulation of Osx through phosphorylation modification. Interestingly, different GSK-3 isoforms phosphorylate Osx in a different manner, although the catalytic domains of them exhibit 97\% sequence homology. Particularly, GSK-3 $\alpha$ phosphorylated Osx at Ser76/80 sites and up-regulated the osteogenic activity of Osx, whereas GSK-3 $\beta$ increased the stability and transactivation activity of Osx through phosphorylation of the newly identified site S422 (Xu et al., 2015). Similarly, the phosphorylation of Ser76/80 of Osx is also important for Pin1 interaction and function (Lee S. H. et al., 2015). What's more, p38-mediated phosphorylation of Osx at Ser-73/77 enhanced the recruitment of coactivators and then transcriptionally active complexes formed. Further study showed that p38-mediated phosphorylation of Osx increases its interaction with the transcriptional coactivators p300 and Brg1 (Ortuño et al., 2010).

Like phosphorylation, acetylation is a universal modification of proteins by increasing or decreasing the DNA binding and transcriptional activity of transcription factors. CREB binding protein (CBP) co-transfection contributing to Osx acetylation significantly delayed Osx degradation and conversely, histone deacetylase 4 (HDAC4) co-transfection involved in the deacetylation of Osx significantly accelerated Osx degradation. CBP interacts with Osx as a transcription coactivator in vivo, resulting in acetylation of the two lysine residues at the
C-terminus of Osx. Further studies have shown that Osx acetylation increases its binding to the promoter of the target genes such as Alp, Bsp, Col1a1 and Osteocalcin (Lu et al., 2016). These facts demonstrated that acetylation of Osx enhances its stability and transcription activity. And Osx activity is required for the osteogenic differentiation of $\mathrm{C} 2 \mathrm{C} 12$ cells. Therefore, Osx acetylation is necessary to promote osteoblast differentiation. Recently, the effect of Osx acetylation on the osteogenic differentiation of vascular smooth muscle cells (VSMCs) was also studied. After the knockdown of the histone deacetylase Hdac9, the expression of Osx mRNA remained unchanged while the protein expression level was significantly enhanced and then resulted in the enhancement of VSMCs calcification in vitro. This process may be mediated by acetylation of Osx (He et al., 2020). It has been confirmed that both endogenous and exogenous Osx protein can be acetylated. Generally, acetylation inhibits DNA binding when the acetylation sites are located in the DNA binding domain, and if they are adjacent to the DNA binding domain, DNA binding is activated. A recent study has identified K307 and K312 as the acetylation sites of Osx (Lu et al., 2016). Among them, $\mathrm{K} 307$ is close to the $\mathrm{C} 2 \mathrm{H} 2$ DNA binding domain of Osx (from amino acids 309 to 376), while K312 is located at the N-terminus of Osx's DNA-binding domain. It is necessary to take further exploration for understanding of the structural changes of Osx after acetylation and the signal pathway networks about acetylation or deacetylation of Osx, as well as any crosstalk between acetylation and other post-translational modifications.

DNA methylation has been a hot topic of epigenetic studies in the bone development system. The $\mathrm{CpG}$ dinucleotides of the Osx promoter regions were unmethylated in osteogenic cell lines transcribing but methylated in non-osteogenic cell lines, suggesting that DNA methylation plays an important role in cell type-specific expression of Osx (Lee et al., 2006; Sepulveda et al., 2017a). DNA demethylation is accompanied by activation of the Osx gene during osteoblast differentiation, which involves the release of DNA methyltransferases from the Osx promoter (Sepulveda et al., 2017b).

\section{THE POTENTIAL EFFICACY OF OsX FOR THE TREATMENT OF OSTEOLYTIC DISEASES}

In the normal physiological circumstances, bone resorption by osteoclasts and bone formation by osteoblasts maintain a healthy balance. Once the balance of this coupled process is broken, the molecular characteristics of the bone microenvironment change. As a result, osteolytic lesions occur, eliciting severe bone pain and fractures.

Osteoporosis is an osteolytic disease resulted from imbalance in bone homeostasis. It is well-known that estrogen (ER) therapy can significantly achieve anti-fracture efficacy, especially for postmenopausal women (Farr et al., 2019). Osx is also involved in osteoporosis treatment. However, ER therapy is usually accompanied by increased risk of breast, ovarian and endometrial cancer, which eventually leads to its diminished application clinically. In addition, as the only drug stimulating bone 
formation approved by Food and Drug Administration (FDA), Parathyroid hormone (PTH) has been proved to increase the Osx expression levels. However, it is related to osteosarcoma and can only be used for 2 years (Arumugam et al., 2019; Yang et al., 2019). Therefore, big efforts are underway to investigate new drugs or find serendipitous effects with old drugs in order to gain better therapy efficacy and minimize potential harms of long-term drug exposure (Stringhetta-Garcia et al., 2016; Qaseem et al., 2017; Haryati et al., 2018; Farr et al., 2019; Yoon et al., 2019). Besides, some natural extracts have been identified to promote osteogenic differentiation via Osx in the treatment of osteoporosis (Choi et al., 2016; Yashan et al., 2017; Wang et al., 2018; Chai et al., 2019; ElMakawy et al., 2020). They positively regulate the transcriptional expression and enhance the activity of Osx via different signaling pathways. Recent research has illustrated that the initial anabolic response after mechanical loading is based on the activation and proliferation of Osx lineage cells, but not the differentiation of progenitor cells (Zannit and Silva, 2019). Low intensity pulsed ultrasound (LIPUS) has been proven successful recoveries from non-unions, delayed unions and fracture of the bone in both animal experiments and clinical treatments. The underlying mechanism revealed that LIPUS-mediated mechanism of osteogenic differentiation may be achieved via upregulation of BMP2 expression and through activation of the BMP/Smad canonical pathway, and then increased Osx expression (Maung et al., 2020).

In addition to osteoporosis, Osx may be an attractive therapeutic target for the control of other osteolytic diseases such as osteosarcoma and bone metastasis of cancers. The expression of Osx was decreased in murine osteosarcoma cells compared with normal mouse osteoblasts. The transfection of Osx into K7M2 cells altered the osteolytic morphology of the tumors. More specifically, the expression of Osx suppressed the osteolytic phenotype (Cao et al., 2005). Decreased Osx expression would result in decreased osteoblast differentiation and increased osteoclast activity leading to lytic destruction as the tumor cells invade the normal bone. Multiple myeloma (MM) is a malignancy to involve the skeleton with patients developing osteolytic bone lesions. A proteasome inhibitor and immunomodulatory drug bortezomib has been introduced in the therapy of MM. when treatment with $10 \mathrm{nM}$ of bortezomib, an increase of Osx RNA transcription both in normal and MM osteoblasts were observed. In the myeloma microenvironment, bortezomib has the ability to stimulate osteoblast differentiation by increasing Osx levels during osteogenesis and inhibit osteoclast differentiation by reducing the induction of osteoclast marker genes and proteins like NFATc1 (De Matteo et al., 2010; Kim et al., 2018; Wang H. et al., 2020). On the contrary, another proteasome inhibitor and immunomodulatory drug named lenalidomide induces osteoblast differentiation by inhibiting the secretion of osteoclastogenic factors which reflects the inhibitory effect exerted on osteogenic cells, but have no effect on Runx2 and Osx transcription (De Matteo et al., 2010). There is a strong nuclear expression of Osx in osteoid osteomas and osteoblastomas, while the expression of Osx in chondromyxoid fibromas and
TABLE 2 | The treatment for different osteolytic diseases by targeting Osx.

\begin{tabular}{|c|c|c|c|}
\hline Drug and trials & $\begin{array}{l}\text { Disease or } \\
\text { cells }\end{array}$ & Mechanisms & References \\
\hline Estrogen (ER) & Osteoporosis & $\begin{array}{l}\text { By elevating the expressions } \\
\text { of Runx } 2 \text { and Osx }\end{array}$ & $\begin{array}{l}\text { Han et al., } \\
2020\end{array}$ \\
\hline $\begin{array}{l}\text { Parathyroid } \\
\text { hormone (PTH) }\end{array}$ & $\begin{array}{l}\text { Dental pulp } \\
\text { stem cells }\end{array}$ & $\begin{array}{l}\text { By activating Erk and p38 } \\
\text { signaling pathways and } \\
\text { elevating Osx expression }\end{array}$ & $\begin{array}{l}\text { Ge et al., } \\
2020\end{array}$ \\
\hline Pseudoshikonin I & C2C12 cells & $\begin{array}{l}\text { By stimulating Osx and Runx2 } \\
\text { via the Akt and Pka signaling } \\
\text { pathways }\end{array}$ & $\begin{array}{l}\text { Choi et al., } \\
2018\end{array}$ \\
\hline Gushukang (GSK) & Osteoporosis & $\begin{array}{l}\text { By enhancing BMP2/Smads } \\
\text { signaling pathway and } \\
\text { elevating Osx expression }\end{array}$ & $\begin{array}{l}\text { Chai et al., } \\
2019\end{array}$ \\
\hline $\begin{array}{l}\text { Strength training } \\
\text { and Raloxifene }\end{array}$ & Osteopenia & $\begin{array}{l}\text { By stimulating/reducing the } \\
\text { genesis and activity of } \\
\text { osteoblasts/osteoclasts }\end{array}$ & $\begin{array}{l}\text { Stringhetta- } \\
\text { Garcia et al., } \\
2016\end{array}$ \\
\hline $\begin{array}{l}\text { Turnip bioactive } \\
\text { lipids }\end{array}$ & Osteoporosis & $\begin{array}{l}\text { By activating Osx and } \\
\text { suppressing Cathepsin } \mathrm{K} \text { and } \\
\text { TNF- } \alpha \text { signaling }\end{array}$ & $\begin{array}{l}\text { El-Makawy } \\
\text { et al., } 2020\end{array}$ \\
\hline Remifentanil & C2C12 cells & $\begin{array}{l}\text { By upregulating Osx and } \\
\text { Runx2 expression. }\end{array}$ & $\begin{array}{l}\text { Yoon et al., } \\
2019\end{array}$ \\
\hline $\begin{array}{l}\text { Low intensity } \\
\text { pulsed } \\
\text { ultrasound(LIPUS) }\end{array}$ & $\begin{array}{l}\text { Periosteum- } \\
\text { derived } \\
\text { cells }\end{array}$ & $\begin{array}{l}\text { By upregulating Osx expression } \\
\text { through activation of the } \\
\text { BMP/Smad canonical pathway }\end{array}$ & $\begin{array}{l}\text { Maung et al. } \\
2020\end{array}$ \\
\hline Bortezomib & $\begin{array}{l}\text { Multiple } \\
\text { myeloma }\end{array}$ & $\begin{array}{l}\text { By increasing Osx expression } \\
\text { and synthesizing the final } \\
\text { differentiation markers in } \\
\text { osteogenesis }\end{array}$ & $\begin{array}{l}\text { De Matteo } \\
\text { et al., } 2010\end{array}$ \\
\hline Lenalidomide & $\begin{array}{l}\text { Multiple } \\
\text { myeloma }\end{array}$ & $\begin{array}{l}\text { By inhibiting the secretion of } \\
\text { osteoclastogenic factors } \\
\text { exerting on osteogenic cells } \\
\text { negatively and no effect on } \\
\text { Runx2 and Osx transcription }\end{array}$ & $\begin{array}{l}\text { De Matteo } \\
\text { et al., } 2010\end{array}$ \\
\hline
\end{tabular}

chondroblastomas are negative generally, which represent a novel marker in assessing chondroblastic and osteoblastic lineage differentiation of bone tumors (Dancer et al., 2010). The potential role of Osx in chondroblastoma are required to be explored indeeply.

Obviously, these studies suggest that Osx has become one of the few downstream specific transcription factors directly regulated by ER or other alternative drugs in the treatment of osteolytic diseases as shown in Table 2. And Osx might be a therapeutic target for osteosarcoma and other osteolytic diseases. Therefore, we would conclude that Osx-mediated mechanism of osteogenic differentiation points out the direction for exploitation of novel bone disease therapy strategies.

\section{CONCLUSION}

Overall, the current literatures have demonstrated that Osx plays a critical role in osteogenesis differentiation. In the last 10 years, the mechanism of Osx in osteoblast differentiation and bone formation are further understood. The efforts in designing new drugs steadily increased due to the recognition that the significance of bone health. Noteworthy, Osx is involved in the complex communications among different bone cells and plays a role in the bone micro-environment. What's more, Osx plays an 
important role in the treatment of osteolytic diseases. And Osx may be an attractive therapeutic target for the control of other osteolytic diseases. As more and more key genes and regulatory mechanisms of osteolytic diseases are discovered, medication of osteolytic diseases with new mechanisms is foreseeable in the future. We believe that the research on Osx and osteolytic diseases in the future will mainly focus on the following aspects: (1) The interaction between bone formation-related protein and Osx during osteogenic differentiation as well as their underlying molecular mechanisms remains to be further studied; (2) The new molecular mechanism of Osx regulated by miRNAs and lncRNAs remains to be explored, which may provide a potential target for the treatment of osteoporosis;(3) More effective and safer Osx-targeted drugs are needed to be further developed for the treatment of osteolytic diseases.

\section{REFERENCES}

Abdallah, B. M., Alzahrani, A. M., and Kassem, M. (2018). Secreted Clusterin protein inhibits osteoblast differentiation of bone marrow mesenchymal stem cells by suppressing ERK1/2 signaling pathway. Bone 110, 221-229. doi: 10 . 1016/j.bone.2018.02.018

Arumugam, B., Vishal, M., Shreya, S., Malavika, D., Rajpriya, V., He, Z., et al. (2019). Parathyroid hormone-stimulation of Runx2 during osteoblast differentiation via the regulation of lnc-SUPT3H-1:16 (RUNX2AS1:32) and miR-6797-5p. Biochimie 158, 43-52. doi: 10.1016/j.biochi.2018. 12.006

Azetsu, Y., Inohaya, K., Takano, Y., Kinoshita, M., Tasaki, M., and Kudo, A. (2017). The sp7 gene is required for maturation of osteoblast-lineage cells in medaka (Oryzias latipes) vertebral column development. Dev. Biol. 431, 252-262. doi: 10.1016/j.ydbio.2017.09.010

Baek, W. Y., and Kim, J. E. (2011). Gene alterations by osteoblast-specific transcription factor osterix in postnatal bone formation. Osteoporosis 9, 51-56.

Barbuto, R., and Mitchell, J. (2013). Regulation of the osterix (Osx, Sp7) promoter by osterix and its inhibition by parathyroid hormone. J. Mol. Endocrinol. 51, 99-108. doi: 10.1530/jme-12-0251

Calabrese, G. M., Mesner, L. D., Stains, J. P., Tommasini, S. M., Horowitz, M. C., Rosen, C. J., et al. (2017). Integrating GWAS and co-expression network data identifies bone mineral density genes SPTBN1 and MARK3 and an osteoblast functional module. Cell Syst. 4, 46-59.e4.

Canalis, E., Schilling, L., Eller, T., and Yu, J. (2020). Nuclear factor of activated T cells 1 and 2 are required for vertebral homeostasis. J. Cell. Physiol. 235, 8520-8532. doi: 10.1002/jcp.29696

Cao, Y., Zhou, Z., de Crombrugghe, B., Nakashima, K., Guan, H., Duan, X., et al. (2005). Osterix, a transcription factor for osteoblast differentiation, mediates antitumor activity in murine osteosarcoma. Cancer Res. 65, 1124-1128. doi: 10.1158/0008-5472.Can-04-2128

Cao, Z., Liu, R., Zhang, H., Liao, H., Zhang, Y., Hinton, R. J., et al. (2015). Osterix controls cementoblast differentiation through downregulation of Wntsignaling via enhancing DKK1 expression. Int. J. Biol. Sci. 11, 335-344. doi: 10.7150/ijbs.10874

Caparros-Martin, J., Aglan, M., Temtamy, S., Martinez-Glez, V., Valencia, M., Tenorio, J., et al. (2013). "OSX/SP7 mutations and osteogenesis imperfecta," in Osteogenesis Imperfecta: A Translational Approach to Brittle Bone Disease, eds J. R. Shapiro, P. H. Byers, F. H. Glorieux, and P. Sponsellor (Amsterdam: Elsevier), 173-179. doi: 10.1016/B978-0-12-397165-4.00018-6

Chai, S., Wan, L., Wang, J. L., Huang, J. C., and Huang, H. X. (2019). Gushukang inhibits osteocyte apoptosis and enhances BMP-2/Smads signaling pathway in ovariectomized rats. Phytomedicine 64:153063. doi: 10.1016/j.phymed.2019. 153063

Chen, D., Tian, W., Li, Y., Tang, W., and Zhang, C. (2012). Osteoblast-specific transcription factor Osterix (Osx) and HIF-1 $\alpha$ cooperatively regulate gene expression of vascular endothelial growth factor (VEGF). Biochem. Biophys. Res. Commun. 424, 176-181. doi: 10.1016/j.bbrc.2012.06.104

\section{AUTHOR CONTRIBUTIONS}

GW and YX conceived of this review. QL drafted this manuscript and designed the figures. ML conducted the literature investigation. All the authors provided the critical feedback, contributed to the discussion on the manuscript writing and revising, and approved the manuscript.

\section{FUNDING}

This work was received financial support from the National Natural Science Foundation of China (NSFC) (No. 81670809) and the Science and Technology Research Fund of Hunan Provincial Education Department.

Chen, X., Wang, Z., Duan, N., Zhu, G., Schwarz, E. M., and Xie, C. (2018). Osteoblast-osteoclast interactions. Connect. Tissue Res. 59, 99-107. doi: 10. 1080/03008207.2017.1290085

Chen, Y., Chen, M., Xue, T., Li, G., Wang, D., Shang, P., et al. (2019). Osteocytic connexin 43 channels affect fracture healing. J. Cell. Physiol. 234, 19824-19832. doi: $10.1002 /$ jcp. 28581

Choi, Y. H., Gu, Y. M., Oh, J. W., and Lee, K. Y. (2011a). Osterix is regulated by Erk1/2 during osteoblast differentiation. Biochem. Biophys. Res. Commun. 415, 472-478. doi: 10.1016/j.bbrc.2011.10.097

Choi, Y. H., Han, Y., Jin, S. W., Lee, G. H., Kim, G. S., Lee, D. Y., et al. (2018). Pseudoshikonin I enhances osteoblast differentiation by stimulating Runx2 and Osterix. J. Cell. Biochem. 119, 748-757. doi: 10.1002/jcb.26238

Choi, Y. H., Han, Y., Lee, S. H., Jin, Y. H., Bahn, M., Hur, K. C., et al. (2015). $\mathrm{Cbl}-\mathrm{b}$ and $\mathrm{c}-\mathrm{Cbl}$ negatively regulate osteoblast differentiation by enhancing ubiquitination and degradation of Osterix. Bone 75, 201-209. doi: 10.1016/j. bone.2015.02.026

Choi, Y. H., Jeong, H. M., Jin, Y.-H., Li, H., Yeo, C.-Y., and Lee, K.-Y. (2011b). Akt phosphorylates and regulates the osteogenic activity of Osterix. Biochem. Biophys. Res. Commun. 411, 637-641. doi: 10.1016/j.bbrc.2011.07.009

Choi, Y. H., Kim, G. S., Choi, J. H., Jin, S. W., Kim, H. G., Han, Y., et al. (2016). Ethanol extract of Lithospermum erythrorhizon Sieb. et Zucc. promotes osteoblastogenesis through the regulation of Runx2 and Osterix. Int. J. Mol. Med. 38, 610-618. doi: 10.3892/ijmm.2016.2655

Dancer, J. Y., Henry, S. P., Bondaruk, J., Lee, S., Ayala, A. G., de Crombrugghe, B., et al. (2010). Expression of master regulatory genes controlling skeletal development in benign cartilage and bone forming tumors. Hum. Pathol. 41, 1788-1793. doi: 10.1016/j.humpath.2010.06.008

De Matteo, M., Brunetti, A. E., Maiorano, E., Cafforio, P., Dammacco, F., and Silvestris, F. (2010). Constitutive down-regulation of Osterix in osteoblasts from myeloma patients: in vitro effect of Bortezomib and Lenalidomide. Leuk. Res. 34, 243-249. doi: 10.1016/j.leukres.2009.07.017

El-Makawy, A. I., Ibrahim, F. M., Mabrouk, D. M., Abdel-Aziem, S. H., Sharaf, H. A., and Ramadan, M. F. (2020). Efficiency of turnip bioactive lipids in treating osteoporosis through activation of Osterix and suppression of Cathepsin K and TNF-alpha signaling in rats. Environ. Sci. Pollut. Res. Int. 27, 20950-20961. doi: 10.1007/s11356-020-08540-7

Farr, J. N., Rowsey, J. L., Eckhardt, B. A., Thicke, B. S., Fraser, D. G., Tchkonia, T., et al. (2019). Independent roles of estrogen deficiency and cellular senescence in the pathogenesis of osteoporosis: evidence in young adult mice and older humans. J. Bone Miner. Res. 34, 1407-1418. doi: 10.1002/jbmr.3729

Felber, K., Elks, P. M., Lecca, M., and Roehl, H. H. (2015). Expression of osterix is regulated by FGF and Wnt/beta-catenin signalling during Osteoblast differentiation. PLoS One 10:e0144982. doi: 10.1371/journal.pone.0144982

Fu, H., Doll, B., Mcnelis, T., and Hollinger, J. O. (2010). Osteoblast differentiation in vitro and in vivo promoted by Osterix. J. Biomed. Mater. Res. A 83A, 770-778. doi: 10.1002/jbm.a.31356

Fu, X., Li, Y., Huang, T., Yu, Z., Ma, K., Yang, M., et al. (2018). Runx2/Osterix and zinc uptake synergize to orchestrate osteogenic differentiation and citrate 
containing bone apatite formation. Adv. Sci. 5:1700755. doi: 10.1002/advs. 201700755

Gamez, B., Rodriguez-Carballo, E., Bartrons, R., Rosa, J. L., and Ventura, F. (2013). MicroRNA-322 (miR-322) and its target protein Tob2 modulate Osterix (Osx) mRNA stability. J. Biol. Chem. 288, 14264-14275. doi: 10.1074/jbc.M112. 432104

Gao, M., Su, Q., Liang, T., Ma, J., and Zou, X. (2018). Transcriptional activation of ENPP1 by osterix in osteoblasts and osteocytes. Eur. Cell. Mater. 36, 1-14. doi: 10.22203/ecm.v036a01

Gao, Y., Jheon, A., Nourkeyhani, H., Kobayashi, H., and Ganss, B. (2004). Molecular cloning, structure, expression, and chromosomal localization of the human Osterix (SP7) gene. Gene 341, 101-110. doi: 10.1016/j.gene.2004. 05.026

Gao, Y., Xiao, F., Wang, C., Wang, C., Cui, P., Zhang, X., et al. (2018). Long noncoding RNA MALAT1 promotes osterix expression to regulate osteogenic differentiation by targeting miRNA-143 in human bone marrow-derived mesenchymal stem cells. J. Cell. Biochem. 119, 6986-6996. doi: 10.1002/jcb. 26907

Ge, X., Li, Z., Jing, S., Wang, Y., Li, N., Lu, J., et al. (2020). Parathyroid hormone enhances the osteo/odontogenic differentiation of dental pulp stem cells via ERK and P38 MAPK pathways. J. Cell. Physiol. 235, 1209-1221. doi: 10.1002/ jcp. 29034

Han, K., Wang, F., Yu, M., and Xu, B. (2020). Estrogen promotes osteogenic differentiation of bone marrow stem cells in patients with postmenopausal osteoporosis by elevating the expressions of Runx-2 and Osterix. Panminerva Med. doi: 10.23736/s0031-0808.19.03791-1 [Epub ahead of print].

Han, Y., Cho, D. H., Chung, D. J., and Lee, K. Y. (2016a). Osterix plays a critical role in BMP4-induced promoter activity of connexin43. Biochem. Biophys. Res. Commun. 478, 683-688. doi: 10.1016/j.bbrc.2016.08.007

Han, Y., Kim, C. Y., Cheong, H., and Lee, K. Y. (2016b). Osterix represses adipogenesis by negatively regulating PPARgamma transcriptional activity. Sci. Rep. 6:35655. doi: 10.1038/srep35655

Han, Y., Kim, Y. M., Kim, H. S., and Lee, K. Y. (2017). Melatonin promotes osteoblast differentiation by regulating Osterix protein stability and expression. Sci. Rep. 7:5716. doi: 10.1038/s41598-017-06304-x

Haryati, A. H., Jamia, J., Nor, A., Khairana, H., Noor, M. S., Norazlina, M., et al. (2018). Demethylbelamcandaquinone B (Dmcq B) is the active compound of Marantodes pumilum var. alata (Blume) Kuntze with osteoanabolic activities. Molecules 23:1686. doi: 10.3390/molecules23071686

Hayami, T., Kapila, Y. L., and Kapila, S. (2011). Divergent upstream osteogenic events contribute to the differential modulation of MG63 cell osteoblast differentiation by MMP-1 (collagenase-1) and MMP-13 (collagenase-3). Matrix Biol. 30, 281-289. doi: 10.1016/j.matbio.2011.04.003

He, P., Yu, H., Jiang, L., Chen, Z., Wang, S., Macrae, V. E., et al. (2020). Hdac9 inhibits medial artery calcification through down-regulation of Osterix. Vasc. Pharmacol. 132:106775. doi: 10.1016/j.vph.2020.106775

He, S., Yang, S., Zhang, Y., Li, X., Gao, D., Zhong, Y., et al. (2019). LncRNA ODIR1 inhibits osteogenic differentiation of hUC-MSCs through the FBXO25/H2BK120ub/H3K4me3/OSX axis. Cell Death Dis. 10:947. doi: 10. 1038/s41419-019-2148-2

Hojo, H., Ohba, S., He, X., Lai, L. P., and McMahon, A. P. (2016). Sp7/Osterix is restricted to bone-forming vertebrates where it acts as a Dlx co-factor in osteoblast specification. Dev. Cell 37, 238-253. doi: 10.1016/j.devcel.2016. 04.002

Huang, C., Geng, J., Wei, X., Zhang, R., and Jiang, S. (2016). MiR-144-3p regulates osteogenic differentiation and proliferation of murine mesenchymal stem cells by specifically targeting Smad4. FEBS Lett. 590, 795-807. doi: 10.1002/18733468.12112

Jiang, Y., Wu, W., Jiao, G., Chen, Y., and Liu, H. (2019). LncRNA SNHG1 modulates p38 MAPK pathway through Nedd4 and thus inhibits osteogenic differentiation of bone marrow mesenchymal stem cells. Life Sci. 228, 208-214. doi: 10.1016/j.lfs.2019.05.002

Jiao, W., Zhang, D., Wang, D., Xu, R., Tang, L., Zhao, M., et al. (2019). MicroRNA638 inhibits human aortic valve interstitial cell calcification by targeting Sp7. J. Cell. Mol. Med. 23, 5292-5302. doi: 10.1111/jcmm.14405

Jing, H., Su, X., Gao, B., Shuai, Y., Chen, J., Deng, Z., et al. (2018). Epigenetic inhibition of Wnt pathway suppresses osteogenic differentiation of BMSCs during osteoporosis. Cell Death Dis. 9:176. doi: 10.1038/s41419-017-0231-0
Karieb, S., and Fox, S. W. (2012). Zinc modifies the effect of phyto-oestrogens on osteoblast and osteoclast differentiation in vitro. Br. J. Nutr. 108, 1736-1745. doi: 10.1017/S0007114511007355

Kawane, T., Komori, H., Liu, W., Moriishi, T., Miyazaki, T., Mori, M., et al. (2014). Dlx 5 and mef2 regulate a novel runx2 enhancer for osteoblast-specific expression. J. Bone Miner. Res. 29, 1960-1969. doi: 10.1002/jbmr.2240

Kemp, J. P., Morris, J. A., Medina-Gomez, C., Forgetta, V., and Evans, D. M. (2017). Identification of 153 new loci associated with heel bone mineral density and functional involvement of GPC6 in osteoporosis. Nat. Genet. 49, 1468-1475. doi: 10.1038/ng.3949

Kim, D., Ko, Y., Park, M., Kim, B., Sohn, H., and Lim, W. (2019). Regulation of osteosclerosis by inoculated Cd133(+) PC3 Cells in bone-marrow microenvironmental niches. JBMR Plus 3:e10189. doi: 10.1002/jbm4.10189

Kim, S. H., Kim, M. O., Kim, H. J., Neupane, S., Kim, H. J., Lee, J. H., et al. (2018). Bortezomib prevents ovariectomy-induced osteoporosis in mice by inhibiting osteoclast differentiation. J. Bone Miner. Metab. 36, 537-546. doi: 10.1007/s00774-017-0871-2

Klein-Nulend, J., Bakker, A. D., Bacabac, R. G., Vatsa, A., and Weinbaum, S. (2013). Mechanosensation and transduction in osteocytes. Bone 54, 182-190. doi: 10.1016/j.bone.2012.10.013

Koga, T., Matsui, Y., Asagiri, M., Kodama, T., and Takayanagi, H. (2005). NFAT and Osterix cooperatively regulate bone formation. Nat. Med. 11, 880-885. doi: $10.1038 / \mathrm{nm} 1270$

Komori, T. (2018). Runx2, an inducer of osteoblast and chondrocyte differentiation. Histochem. Cell Biol. 149, 313-323. doi: 10.1007/s00418018-1640-6

Kusu, N., Laurikkala, J., Imanishi, M., Usui, H., Konishi, M., Miyake, A., et al. (2003). Sclerostin is a novel secreted osteoclast-derived bone morphogenetic protein antagonist with unique ligand specificity. J. Biol. Chem. 278, 24113 24117. doi: 10.1074/jbc.M301716200

Landgraf, P., Rusu, M., Sheridan, R., Sewer, A., Iovino, N., Aravin, A., et al. (2007). A mammalian microRNA expression atlas based on small RNA library sequencing. Cell 129, 1401-1414. doi: 10.1016/j.cell.2007.04.040

Lee, D. S., Choung, H. W., Kim, H. J., Gronostajski, R. M., Yang, Y. I., Ryoo, H. M., et al. (2014). NFI-C regulates osteoblast differentiation via control of osterix expression. Stem Cells 32, 2467-2479. doi: 10.1002/stem.1733

Lee, D. S., Roh, S. Y., and Park, J. C. (2018). The Nfic-osterix pathway regulates ameloblast differentiation and enamel formation. Cell Tissue Res. 374, 531-540. doi: 10.1007/s00441-018-2901-3

Lee, H., Min, S., Song, Y., Park, Y. H., and Park, J. B. (2019). Bone morphogenetic protein-7 upregulates genes associated with osteoblast differentiation, including collagen I, Sp7 and IBSP in gingiva-derived stem cells. Exp. Ther. Med. 18, 2867-2876. doi: 10.3892/etm.2019.7904

Lee, J. Y., Lee, Y. M., Kim, M. J., Choi, J. Y., Park, E. K., Kim, S. Y., et al. (2006). Methylation of the mouse DIx5 and Osx gene promoters regulates cell type-specific gene expression. Mol. Cells 22, 182-188.

Lee, M. H., Kwon, T. G., Park, H. S., Wozney, J. M., and Ryoo, H. M. (2003). BMP2 -induced Osterix expression is mediated by Dlx 5 but is independent of Runx 2 . Biochem. Biophys. Res. Commun. 309, 689-694. doi: 10.1016/j.bbrc.2003. 08.058

Lee, S. H., Jeong, H. M., Han, Y., Cheong, H., Kang, B. Y., and Lee, K. Y. (2015). Prolyl isomerase Pin1 regulates the osteogenic activity of Osterix. Mol. Cell. Endocrinol. 400, 32-40. doi: 10.1016/j.mce.2014.11.017

Lee, S. J., Lee, E. H., Park, S. Y., and Kim, J. E. (2017). Induction of fibrillin2 and periostin expression in Osterix-knockdown MC3T3-E1 cells. Gene 596, 123-129. doi: 10.1016/j.gene.2016.10.018

Lee, Y. J., Park, S. Y., Lee, S. J., Boo, Y. C., Choi, J. Y., and Kim, J. E. (2015). Ucma, a direct transcriptional target of Runx2 and Osterix, promotes osteoblast differentiation and nodule formation. Osteoarthr. Cartil. 23, 1421-1431. doi: 10.1016/j.joca.2015.03.035

Li, Y., Hu, W., Han, G., Lu, W., Jia, D., Hu, M., et al. (2018a). Involvement of bone morphogenetic protein-related pathways in the effect of aucubin on the promotion of osteoblast differentiation in MG63cells. Chem. Biol. Interact. 283, 51-58. doi: 10.1016/j.cbi.2018.02.005

Li, Y., Jin, D., Xie, W., Wen, L., Chen, W., Xu, J., et al. (2018b). PPAR$\gamma$ and Wnt regulate the differentiation of MSCs into adipocytes and osteoblasts respectively. Curr. Stem Cell Res. Ther. 13, 185-192. doi: 10.2174/ $1574888 \times 12666171012141908$ 
Li, Z., Wang, W., Xu, H., Ning, Y., Fang, W., Liao, W., et al. (2017). Effects of altered CXCL12/CXCR4 axis on BMP2/Smad/Runx2/Osterix axis and osteogenic gene expressions during osteogenic differentiation of MSCs. Am. J. Transl. Res. 9, 1680-1693.

Liu, B., Wu, S., Han, L., and Zhang, C. (2015). beta-catenin signaling induces the osteoblastogenic differentiation of human pre-osteoblastic and bone marrow stromal cells mainly through the upregulation of osterix expression. Int. J. Mol. Med. 36, 1572-1582. doi: 10.3892/ijmm.2015.2382

Liu, L., He, F. M., Li, L. L., and Hu, J. A. (2004). [The expression of MMP-9, MMP-2 in the remodeling bone tissue around implant during unloaded period]. Hua Xi Kou Qiang Yi Xue Za Zhi 22, 325-327.

Liu, L., Zeng, D., Chen, Y., Zhou, J., Liao, Y., and Shi, B. (2020). Microarc oxidation surface of titanium implants promote osteogenic differentiation by activating ERK1/2-miR-1827-Osterix. In Vitro Cell. Dev. Biol. Anim. 56, 296-306. doi: 10.1007/s11626-020-00444-7

Lu, J., Qu, S., Yao, B., Xu, Y., Jin, Y., Shi, K., et al. (2016). Osterix acetylation at K307 and $\mathrm{K} 312$ enhances its transcriptional activity and is required for osteoblast differentiation. Oncotarget 7, 37471-37486. doi: 10.18632/oncotarget.9650

Machida, M., Dubousset, J., Yamada, T., Kimura, J., Saito, M., Shiraishi, T., et al. (2006). Experimental scoliosis in melatonin-deficient C57BL/6J mice without pinealectomy. J. Pineal Res. 41, 1-7. doi: 10.1111/j.1600-079X.2005.00312.x

Matsubara, T., Kida, K., Yamaguchi, A., Hata, K., Ichida, F., Meguro, H., et al. (2008). BMP2 regulates Osterix through Msx2 and Runx2 during osteoblast differentiation. J. Biol. Chem. 283, 29119-29125. doi: 10.1074/jbc.M801774200

Maung, W. M., Nakata, H., Miura, M., Miyasaka, M., Kim, Y. K., Kasugai, S., et al. (2020). Low intensity pulsed ultrasound stimulates osteogenic differentiation of periosteal cells in vitro. Tissue Eng. Part A. doi: 10.1089/ten.TEA.2019.0331 [Epub ahead of print].

Milona, M. A., Gough, J. E., and Edgar, A. J. (2003). Expression of alternatively spliced isoforms of human Sp7 in osteoblast-like cells. BMC Genomics 4:43. doi: 10.1186/1471-2164-4-43

Moon, Y. J., Yun, C.-Y., Choi, H., Kim, J. R., Park, B.-H., and Cho, E.-S. (2018). Osterix regulates corticalization for longitudinal bone growth via integrin $\beta 3$ expression. Exp. Mol. Med. 50, 1-11. doi: 10.1038/s12276-018-0119-9

Nakajima, K., Kho, D. H., Yanagawa, T., Harazono, Y., Gao, X., Hogan, V., et al. (2014). Galectin-3 inhibits osteoblast differentiation through notch signaling. Neoplasia 16, 939-949. doi: 10.1016/j.neo.2014.09.005

Nakashima, K., Zhou, X., Kunkel, G., Zhang, Z., Deng, J. M., Behringer, R. R., et al. (2002). The novel zinc finger-containing transcription factor osterix is required for osteoblast differentiation and bone formation. Cell 108, 17-29. doi: 10.1016/s0092-8674(01)00622-5

Nakatani, T., Chen, T., and Partridge, N. C. (2016). MMP-13 is one of the critical mediators of the effect of HDAC4 deletion on the skeleton. Bone 90, 142-151. doi: 10.1016/j.bone.2016.06.010

Nemoto, E., Sakisaka, Y., Tsuchiya, M., Tamura, M., Nakamura, T., Kanaya, S., et al. (2016). Wnt3a signaling induces murine dental follicle cells to differentiate into cementoblastic/osteoblastic cells via an osterix-dependent pathway. J. Periodontal. Res. 51, 164-174. doi: 10.1111/jre.12294

Niger, C., Lima, F., Yoo, D. J., Gupta, R. R., Buo, A. M., Hebert, C., et al. (2011). The transcriptional activity of osterix requires the recruitment of Sp1 to the osteocalcin proximal promoter. Bone 49, 683-692. doi: 10.1016/j.bone.2011. 07.027

Niu, P., Zhong, Z., Wang, M., Huang, G., Xu, S., Hou, Y., et al. (2017). Zinc finger transcription factor Sp7/Osterix acts on bone formation and regulates col10ala expression in zebrafish. Sci. Bull. 62, 174-184. doi: 10.1016/j.scib.2017. 01.009

Oh, J. H., Park, S. Y., de Crombrugghe, B., and Kim, J. E. (2012). Chondrocytespecific ablation of Osterix leads to impaired endochondral ossification. Biochem. Biophys. Res. Commun. 418, 634-640. doi: 10.1016/j.bbrc.2012.01.064

Omoteyama, K., and Takagi, M. (2010). The effects of Sp7/Osterix gene silencing in the chondroprogenitor cell line, ATDC5. Biochem. Biophys. Res. Commun. 403, 242-246. doi: 10.1016/j.bbrc.2010.11.023

Onizuka, S., Iwata, T., Park, S. J., Nakai, K., Yamato, M., Okano, T., et al. (2016). ZBTB16 as a downstream target gene of Osterix regulates osteoblastogenesis of human multipotent mesenchymal stromal cells. J. Cell. Biochem. 117, 24232434. doi: $10.1002 /$ jcb. 25634

Ortuño, M. J., Ruiz-Gaspà, S., Rodríguez-Carballo, E., Susperregui, A. R., Bartrons, R., Rosa, J. L., et al. (2010). p38 regulates expression of osteoblast-specific genes by phosphorylation of Osterix. J. Biol. Chem. 285, 31985-31994. doi: 10.1074/ jbc.M110.123612

Ortuno, M. J., Susperregui, A. R., Artigas, N., Rosa, J. L., and Ventura, F. (2013). Osterix induces Collal gene expression through binding to Spl sites in the bone enhancer and proximal promoter regions. Bone 52, 548-556. doi: 10.1016/ j.bone.2012.11.007

Peng, Y., Shi, K., Wang, L., Lu, J., Li, H., Pan, S., et al. (2013). Characterization of Osterix protein stability and physiological role in osteoblast differentiation. PLoS One 8:e56451. doi: 10.1371/journal.pone.0056451

Pérez-Campo, F. M., Santurtún, A., García-Ibarbia, C., Pascual, M. A., Valero, C., Garcés, C., et al. (2016). Osterix and RUNX2 are transcriptional regulators of sclerostin in human bone. Calcif. Tissue Int. 99, 302-309. doi: 10.1007/s00223016-0144-4

Pivetta, E., Scapolan, M., Pecolo, M., Wassermann, B., Abu-Rumeileh, I., Balestreri, L., et al. (2011). MMP-13 stimulates osteoclast differentiation and activation in tumour breast bone metastases. Breast Cancer Res. 13:R105. doi: 10.1186/ bcr3047

Qaseem, A., Forciea, M. A., McLean, R. M., Denberg, T. D., and Clinical Guidelines Committee of the American College of Physicians, (2017). Treatment of low bone density or osteoporosis to prevent fractures in men and women: a clinical practice guideline update from the American college of physicians. Ann. Intern. Med. 166, 818-839. doi: 10.7326/m15-1361

Qi, J., Hu, K. S., and Yang, H. L. (2015). Roles of TNF- $\alpha$, GSK-3 $\beta$ and RANKL in the occurrence and development of diabetic osteoporosis. Int. J. Clin. Exp. Pathol. 8, 11995-12004.

Qu, S., Wu, J., Bao, Q., Yao, B., Duan, R., Chen, X., et al. (2019). Osterix promotes the migration and angiogenesis of breast cancer by upregulation of S100A4 expression. J. Cell. Mol. Med. 23, 1116-1127. doi: 10.1111/jcmm.14012

Rajamannan, N. M. (2019). TIEG1 is upregulated in Lrp5/6-mediated valve osteogenesis. J. Cell. Biochem. 120, 3362-3366. doi: 10.1002/jcb.27606

Ramazzotti, G., Fiume, R., Chiarini, F., Campana, G., Ratti, S., Billi, A. M., et al. (2019). Phospholipase C- $\beta 1$ interacts with cyclin E in adipose- derived stem cells osteogenic differentiation. Adv. Biol. Regul. 71, 1-9. doi: 10.1016/j.jbior. 2018.11.001

Renn, J., and Winkler, C. (2009). Osterix-mCherry transgenic medaka for in vivo imaging of bone formation. Dev. Dyn. 238, 241-248. doi: 10.1002/dvdy.21836

Rios-Arce, N. D., Dagenais, A., Feenstra, D., Coughlin, B., Kang, H. J., Mohr, S., et al. (2020). Loss of interleukin-10 exacerbates early Type-1 diabetes-induced bone loss. J. Cell. Physiol. 235, 2350-2365. doi: 10.1002/jcp.29141

Sakisaka, Y., Kanaya, S., Nakamura, T., Tamura, M., Shimauchi, H., and Nemoto, E. (2016). p38 MAP kinase is required for Wnt3a-mediated osterix expression independently of Wnt-LRP5/6-GSK3 $\beta$ signaling axis in dental follicle cells. Biochem. Biophys. Res. Commun. 478, 527-532. doi: 10.1016/j.bbrc.2016.07.076

Sepulveda, H., Aguilar, R., Prieto, C. P., Bustos, F., Aedo, S., Lattus, J., et al. (2017a). Epigenetic signatures at the RUNX2-P1 and $\mathrm{Sp} 7$ gene promoters control osteogenic lineage commitment of umbilical cord-derived mesenchymal stem cells. J. Cell. Physiol. 232, 2519-2527. doi: 10.1002/jcp.25627

Sepulveda, H., Villagra, A., and Montecino, M. (2017b). Tet-mediated DNA demethylation is required for SWI/SNF-dependent chromatin remodeling and histone-modifying activities that trigger expression of the Sp7 osteoblast master gene during mesenchymal lineage commitment. Mol. Cell. Biol. 37:e00177-17. doi: 10.1128/MCB.00177-17

Shi, K., Lu, J., Zhao, Y., Wang, L., Li, J., Qi, B., et al. (2013). MicroRNA-214 suppresses osteogenic differentiation of $\mathrm{C} 2 \mathrm{C} 12$ myoblast cells by targeting Osterix. Bone 55, 487-494. doi: 10.1016/j.bone.2013.04.002

Shi, L., Cai, G., Shi, J., Guo, Y., Chen, D., Chen, D., et al. (2016). Ossification of the posterior ligament is mediated by osterix via inhibition of the $\beta$-catenin signaling pathway. Exp. Cell Res. 349, 53-59. doi: 10.1016/j.yexcr.2016.09.019

Sinha, K. M., Yasuda, H., Coombes, M. M., Dent, S. Y., and de Crombrugghe, B. (2010). Regulation of the osteoblast-specific transcription factor Osterix by NO66, a Jumonji family histone demethylase. EMBO J. 29, 68-79. doi: 10.1038/ emboj.2009.332

Sinha, K. M., Yasuda, H., Zhou, X., and de Crombrugghe, B. (2014). Osterix and NO66 histone demethylase control the chromatin of Osterix target genes during osteoblast differentiation. J. Bone Miner. Res. 29, 855-865. doi: 10.1002/jbmr. 2103

Stringhetta-Garcia, C. T., Singulani, M. P., Santos, L. F., Louzada, M. J., Nakamune, A. C., Chaves-Neto, A. H., et al. (2016). The effects of strength training and 
raloxifene on bone health in aging ovariectomized rats. Bone $85,45-54$. doi: 10.1016/j.bone.2015.11.023

Subramaniam, M., Pitel, K. S., Withers, S. G., Drissi, H., and Hawse, J. R. (2016). TIEG1 enhances Osterix expression and mediates its induction by TGFbeta and BMP2 in osteoblasts. Biochem. Biophys. Res. Commun. 470, 528-533. doi: 10.1016/j.bbrc.2016.01.112

Sun, C., Yuan, H., Wang, L., Wei, X., Williams, L., Krebsbach, P. H., et al. (2016). FAK promotes Osteoblast progenitor cell proliferation and differentiation by enhancing Wnt signaling. J. Bone Miner. Res. 31, 2227-2238. doi: 10.1002/jbmr. 2908

Sun, X., Yang, X., Zhao, Y., Li, Y., and Guo, L. (2018). Effects of 17beta-estradiol on mitophagy in the murine MC3T3-E1 osteoblast cell line is mediated via G protein-coupled estrogen receptor and the ERK1/2 signaling pathway. Med. Sci. Monit. 24, 903-911. doi: 10.12659/msm.908705

Sun, Y., Cai, M., Zhong, J., Yang, L., Xiao, J., Jin, F., et al. (2019). The long noncoding RNA lnc-obl facilitates bone formation by upregulating Osterix in osteoblasts. Nat. Metab. 1, 485-496. doi: 10.1038/s42255-019-0053-8

Suske, G., Bruford, E., and Philipsen, S. (2005). Mammalian SP/KLF transcription factors: bring in the family. Genomics 85, 551-556. doi: 10.1016/j.ygeno.2005. 01.005

Takarada, T., Nakazato, R., Tsuchikane, A., Fujikawa, K., Iezaki, T., Yoneda, Y., et al. (2016). Genetic analysis of Runx2 function during intramembranous ossification. Development 143, 211-218. doi: 10.1242/dev.128793

Tang, W., Yang, F., Li, Y., de Crombrugghe, B., Jiao, H., Xiao, G., et al. (2012). Transcriptional regulation of vascular endothelial growth factor (VEGF) by osteoblast-specific transcription factor Osterix (Osx) in osteoblasts. J. Biol. Chem. 287, 1671-1678. doi: 10.1074/jbc.M111.288472

Wang, C. G., Liao, Z., Xiao, H., Liu, H., Hu, Y. H., Liao, Q. D., et al. (2019). LncRNA KCNQ1OT1 promoted BMP2 expression to regulate osteogenic differentiation by sponging miRNA-214. Exp. Mol. Pathol. 107, 77-84. doi: 10.1016/j.yexmp. 2019.01.012

Wang, H., Cui, Y., Luan, J., Zhou, X., Li, C., Li, H., et al. (2017). MiR-5100 promotes osteogenic differentiation by targeting Tob2. J. Bone Miner. Metab. 35, 608-615. doi: 10.1007/s00774-016-0799-y

Wang, H., Zhang, H., Srinivasan, V., Tao, J., Sun, W., Lin, X., et al. (2020). Targeting Bortezomib to bone increases its bone anabolic activity and reduces systemic adverse effects in mice. J. Bone Miner. Res. 35, 343-356. doi: 10.1002/jbmr. 3889

Wang, Q., Zhao, Y., Sha, N., Zhang, Y., Li, C., Zhang, H., et al. (2018). The systemic bone protective effects of Gushukang granules in ovariectomized mice by inhibiting osteoclastogenesis and stimulating osteoblastogenesis. J. Pharmacol. Sci. 136, 155-164. doi: 10.1016/j.jphs.2018.01.007

Wang, Z., Liu, Q., Liu, C., Tan, W., Tang, M., Zhou, X., et al. (2020). Mg(2+) in beta-TCP/Mg- $\mathrm{Zn}$ composite enhances the differentiation of human bone marrow stromal cells into osteoblasts through MAPK-regulated Runx2/Osx. J. Cell. Physiol. 235, 5182-5191. doi: 10.1002/jcp.29395

Wu, J., Zhao, J., Sun, L., Pan, Y., Wang, H., and Zhang, W. B. (2018). Long noncoding RNA H19 mediates mechanical tension-induced osteogenesis of bone marrow mesenchymal stem cells via FAK by sponging miR-138. Bone 108, 62-70. doi: 10.1016/j.bone.2017.12.013

Wu, L., Wu, Y., Lin, Y., Jing, W., Nie, X., Qiao, J., et al. (2007). Osteogenic differentiation of adipose derived stem cells promoted by overexpression of osterix. Mol. Cell. Biochem. 301, 83-92. doi: 10.1007/s11010-006-9399-9

Wu, R., Ruan, J., Sun, Y., Liu, M., Sha, Z., Fan, C., et al. (2018). Long non-coding RNA HIF1A-AS2 facilitates adipose-derived stem cells (ASCs) osteogenic differentiation through miR-665/IL6 axis via PI3K/Akt signaling pathway. Stem Cell Res. Ther. 9:48. doi: 10.1186/s13287-018-1082-z

Wu, Y. F., Matsuo, N., Sumiyoshi, H., and Yoshioka, H. (2010a). Sp7/Osterix is involved in the up-regulation of the mouse pro- $\alpha 1(\mathrm{~V})$ collagen gene $(\mathrm{Col} 5 \mathrm{a} 1)$ in osteoblastic cells. Matrix Biol. 29, 701-706. doi: 10.1016/j.matbio.2010.09.002

Wu, Y. F., Matsuo, N., Sumiyoshi, H., and Yoshioka, H. (2010b). Sp7/Osterix upregulates the mouse pro-alpha3(V) collagen gene (Col5a3) during the osteoblast differentiation. Biochem. Biophys. Res. Commun. 394, 503-508. doi: 10.1016/j. bbrc.2010.02.171

Xiao, W.-l., Zhang, D.-z., Fan, C.-h., and Yu, B.-j. (2015). Intermittent stretching and osteogenic differentiation of bone marrow derived mesenchymal stem cells via the p38MAPK-osterix signaling pathway. Cell. Physiol. Biochem. 36, 1015-1025. doi: 10.1159/000430275
Xiao, Z. S., Hjelmeland, A. B., and Quarles, L. D. (2004). Selective deficiency of the "Bone-related" Runx2-II unexpectedly preserves osteoblast-mediated skeletogenesis. J. Biol. Chem. 279, 20307-20313. doi: 10.1074/jbc.m40110 9200

Xie, J., and Gu, J. (2015). Identification of C-terminal Hsp70-interacting protein as a mediator of tumour necrosis factor action in osteoblast differentiation by targeting osterix for degradation. J. Cell. Mol. Med. 19, 1814-1824. doi: 10.1111/jcmm.12553

Xing, W., Godwin, C., Pourteymoor, S., and Mohan, S. (2019). Conditional disruption of the osterix gene in chondrocytes during early postnatal growth impairs secondary ossification in the mouse tibial epiphysis. Bone Res. 7:24. doi: 10.1038/s41413-019-0064-9

Xu, Y., Yao, B., Shi, K., Lu, J., Jin, Y., Qi, B., et al. (2015). Phosphorylation of Serine 422 increases the stability and transactivation activities of human Osterix. FEBS Lett. 589, 857-864. doi: 10.1016/j.febslet.2015.02.021

Yang, B., Li, S., Chen, Z., Feng, F., He, L., Liu, B., et al. (2020). Amyloid $\beta$ peptide promotes bone formation by regulating $\mathrm{Wnt} / \beta$-catenin signaling and the OPG/RANKL/RANK system. FASEB J. 34, 3583-3593. doi: 10.1096/fj. 201901550R

Yang, F., Tang, W., So, S., de Crombrugghe, B., and Zhang, C. (2010). Sclerostin is a direct target of osteoblast-specific transcription factor osterix. Biochem. Biophys. Res. Commun. 400, 684-688. doi: 10.1016/j.bbrc.2010.08.128

Yang, L., Cheng, P., Chen, C., He, H.-B., Xie, G.-Q., Zhou, H.-D., et al. (2012). miR93/Sp7 function loop mediates osteoblast mineralization. J. Bone Miner. Res. 27, 1598-1606. doi: 10.1002/jbmr.1621

Yang, M., Arai, A., Udagawa, N., Zhao, L., Nishida, D., Murakami, K., et al. (2019). Parathyroid hormone shifts cell fate of a leptin receptor-marked stromal population from adipogenic to osteoblastic lineage. J. Bone Miner. Res. 34, 1952-1963. doi: 10.1002/jbmr.3811

Yang, Y., Huang, Y., Zhang, L., and Zhang, C. (2016). Transcriptional regulation of bone sialoprotein gene expression by Osx. Biochem. Biophys. Res. Commun. 476, 574-579. doi: 10.1016/j.bbrc.2016.05.164

Yano, H., Hamanaka, R., Nakamura-Ota, M., Adachi, S., Zhang, J. J., Matsuo, N., et al. (2014). Sp7/Osterix induces the mouse pro- $\alpha 2$ (I) collagen gene (Colla2) expression via the proximal promoter in osteoblastic cells. Biochem. Biophys. Res. Commun. 452, 531-536. doi: 10.1016/j.bbrc.2014.08.100

Yao, B., Wang, J., Qu, S., Liu, Y., Jin, Y., Lu, J., et al. (2019). Upregulated osterix promotes invasion and bone metastasis and predicts for a poor prognosis in breast cancer. Cell Death Dis. 10:28. doi: 10.1038/s41419-0181269-3

Yashan, Y., Yunxia, L., and Hong, Z. (2017). Clinical study on the effects of Gushukang capsules in treating glucocorticoid induced osteoporosis. Chin. J. Osteoporos. 23, 795-799.

Yoon, J. Y., Kim, T. S., Ahn, J. H., Yoon, J. U., Kim, H. J., and Kim, E. J. (2019). Remifentanil promotes osteoblastogenesis by upregulating Runx2/osterix expression in preosteoblastic C2C12 cells. J. Dent. Anesth. Pain Med. 19, 91-99. doi: 10.17245/jdapm.2019.19.2.91

You, H. C., Jeong, H. M., Jin, Y. H., Li, H., Yeo, C. Y., and Lee, K. Y. (2011). Akt phosphorylates and regulates the osteogenic activity of Osterix. Biochem. Biophys. Res. Commun. 411, 637-641. doi: 10.1016/j.bbrc.2011. 07.009

Yu, T., Graf, M., Renn, J., Schartl, M., Larionova, D., Huysseune, A., et al. (2017). A vertebrate-specific and essential role forosterixin osteogenesis revealed by gene knockout in the teleost medaka. Development 144, 265-271. doi: 10.1242/dev. 139550

Zannit, H. M., and Silva, M. J. (2019). Proliferation and activation of osterix-lineage cells contribute to loading-induced periosteal bone formation in mice. JBMR Plus 3:e10227. doi: 10.1002/jbm4.10227

Zhang, B., Zhang, X., Xiao, J., Zhou, X., Chen, Y., and Gao, C. (2020). Neuropeptide Y upregulates Runx2 and osterix and enhances osteogenesis in mouse MC3T3E1 cells via an autocrine mechanism. Mol. Med. Rep. 22, 4376-4382. doi: 10.3892/mmr.2020.11506

Zhang, C., Tang, W., and Li, Y. (2012). Matrix metalloproteinase 13 (MMP13) is a direct target of osteoblast-specific transcription factor osterix (Osx) in osteoblasts. PLoS One 7:e50525. doi: 10.1371/journal.pone.0050525

Zhang, H., Jiang, Y., Qin, C., Liu, Y., Ho, S. P., and Feng, J. Q. (2015). Essential role of osterix for tooth root but not crown dentin formation. J. Bone Miner. Res. 30, 742-746. doi: 10.1002/jbmr.2391 
Zhang, H., Liu, L., Jiang, C., Pan, K., Deng, J., and Wan, C. (2020). MMP9 protects against LPS-induced inflammation in osteoblasts. Innate Immun. 26, 259-269. doi: $10.1177 / 1753425919887236$

Zhang, J. F., Fu, W., He, M. L., Wang, H., Wang, W. M., Yu, S. C., et al. (2011). MiR-637 maintains the balance between adipocytes and osteoblasts by directly targeting Osterix. Mol. Biol. Cell 22, 3955-3961. doi: 10.1091/mbc.e11-040356

Zhang, S. Y., Gao, F., Peng, C. G., Zheng, C. J., and Wu, M. F. (2018). miR-485-5p promotes osteoporosis via targeting Osterix. Eur. Rev. Med. Pharmacol. Sci. 22, 4792-4799. doi: 10.26355/eurrev_201808_15613

Zhang, Z. H., Jia, X. Y., Fang, J. Y., Chai, H., Huang, Q., She, C., et al. (2020). Reduction of SOST gene promotes bone formation through the Wnt/beta-catenin signalling pathway and compensates particleinduced osteolysis. J. Cell. Mol. Med. 24, 4233-4244. doi: 10.1111/jcmm. 15084

Zhou, X., Zhang, Z., Feng, J. Q., Dusevich, V. M., Sinha, K., Zhang, H., et al. (2010). Multiple functions of Osterix are required for bone growth and homeostasis in postnatal mice. Proc. Natl. Acad. Sci. U.S.A. 107, 12919-12924. doi: 10.1073/ pnas.0912855107

Zhou, Y., Wang, C., Si, J., Wang, B., Zhang, D., Ding, D., et al. (2020). Melatonin up-regulates bone marrow mesenchymal stem cells osteogenic action but suppresses their mediated osteoclastogenesis via MT(2) -inactivated NF-кB pathway. Br. J. Pharmacol. 177, 2106-2122. doi: 10.1111/bph.14972

Conflict of Interest: The authors declare that the research was conducted in the absence of any commercial or financial relationships that could be construed as a potential conflict of interest.

Copyright (c) $2020 \mathrm{Liu}, \mathrm{Li}$, Wang, Xiao, Xiong and Wang. This is an open-access article distributed under the terms of the Creative Commons Attribution License (CC BY). The use, distribution or reproduction in other forums is permitted, provided the original author(s) and the copyright owner(s) are credited and that the original publication in this journal is cited, in accordance with accepted academic practice. No use, distribution or reproduction is permitted which does not comply with these terms. 